Article

\title{
Quantification of Uncertainties from Image Processing and Analysis in Laboratory-Scale DNAPL Release Studies Evaluated by Reflective Optical Imaging
}

\author{
Christian Engelmann 1,2,*D, Luisa Schmidt ${ }^{1,3}$, Charles J. Werth ${ }^{4}$ and Marc Walther ${ }^{1,2}$ \\ 1 Department of Environmental Sciences, Institute of Groundwater Management, Technische Universität \\ Dresden, Bergstraße 66, 01062 Dresden, Germany; luisa.schmidt1@tu-dresden.de (L.S.); \\ marc.walther@tu-dresden.de (M.W.) \\ 2 Department Environmental Informatics, Helmholtz-Centre for Environmental Research-UFZ, \\ Permoserstraße 15, 04318 Leipzig, Germany \\ 3 Department Monitoring and Exploration Technologies, Helmholtz-Centre for Environmental \\ Research-UFZ, Permoserstraße 15, 04318 Leipzig, Germany \\ 4 Department of Civil, Architectural and Environmental Engineering, Bettie Margaret Smith Chair in \\ Environmental Health Engineering, University of Texas at Austin, TX 78705, USA; werth@utexas.edu \\ * Correspondence: christian.engelmann@tu-dresden.de; Tel.: +49-351-463-40552
}

Received: 27 September 2019; Accepted: 25 October 2019; Published: 30 October 2019

\begin{abstract}
Subsurface DNAPL (dense non-aqueous phase liquid) contamination from (un-) intentional spilling typically leads to severe environmental hazards. A large number of studies have demonstrated the relevance of DNAPL source zone geometry for the determination of contaminant plume propagation in groundwater. Optical imaging represents a promising non-invasive method for identifying DNAPL saturation without disturbing multiphase flow dynamics. However, workflow and image analysis methodologies have not been sufficiently developed or described for general application to related experimental efforts. For example, the choice of dye(s) used for phase colorization affects image processing and can bias final estimations of DNAPL saturations. In this study, we perform a series of DNAPL migration and entrapment studies in transparent tanks that are filled with three different types of porous media. Different dyes are used and raw images are acquired. Subsequently, these are used to evaluate a suite of image processing and analysis approaches, which are organized into a workflow. Our approach allows for us to identify key image processing and analysis steps that introduce the most error. Applicable dye configurations led to uncertainties of up to $41 \%$ depending on the selection of processing steps. Based on these findings, it was possible to delineate a flexible framework for image processing and analysis that has the potential for transfer and application in other tank experiment setups.
\end{abstract}

Keywords: DNAPL; source zone geometry; reflective optical imaging; image processing and analysis; contaminant hydrology

\section{Introduction}

The contamination of groundwater by dense non-aqueous phase liquids (DNAPLs) poses tremendous risks for secure water supply and natural environments (e.g., [1,2]). Typical DNAPLs are chlorinated solvents that are used in degreasing and cleaning operations. They are often toxic, carcinogenic, and highly persistent in the environment. DNAPL contamination of groundwater occurs in three (sometimes overlapping) stages [3]: (i) the downward vertical migration of a separate DNAPL 
phase from the spill source to groundwater (e.g., [4]), (ii) the mass transfer of DNAPL components to the aqueous phase via dissolution (e.g., [5]) and (iii) aqueous phase transport of DNAPL components in groundwater. Once DNAPL release from the original spill source has ceased, DNAPL migration will eventually end and a quasi-steady-state DNAPL source zone geometry (SZG; i.e., regions of non-wetting phase covering residual and elevated values for saturation) will form (e.g., [6,7]). This entrapped DNAPL represents a long-term source of contamination to groundwater, and it leads to contaminant plumes that can affect large areas of drinking water aquifers (e.g., [8]). Previous studies have shown that SZG has a strong influence on plume size and geometry (e.g., [9-12]). A large suite of multiphase flow models has been developed to characterize DNAPL migration and subsequent formation of source zones [13]. However, experimental laboratory data for validation is lacking. A major challenge is large errors that occur with existing SZG characterization methods (e.g., induced by indirect approaches) [3], which indicates that improved approaches are needed.

Laboratory-scale experiments provide the greatest opportunity for controlling the system properties and environmental conditions that affect DNAPL migration and entrapment, and to monitor these processes in situ (for a comprehensive overview, please refer to Reference [14]). Liquid or gas sampling methodologies are commonly used to monitor DNAPL migration and entrapment, but they are limited to a fixed number of positions, and their acquisition can disturb DNAPL migration. In contrast, non-invasive imaging methods are preferable. They allow for quasi-continuous monitoring of the entire DNAPL mass without disturbing the flow dynamics. Geophysical methods, such as X-ray tomography (e.g., [15]), electrical resistivity tomography (e.g., [16,17]) and magnetic resonance imaging (e.g., [18]) have been used. They are powerful yet technically demanding and can suffer from calibration and interpretation uncertainties $[14,19,20]$. More promising are optical imaging methods using standard CCD/CMOS cameras. They can be used to detect incoming ultraviolet, infrared and/or visible light, and are economically and technically more accessible. Optical imaging methods have been used by many researchers to investigate processes, such as groundwater flow and solute visualization (e.g., [21,22]), structure monitoring (e.g., [23]), saltwater intrusion (e.g., [24-27]), and NAPL migration (e.g., References [28-42]. However, they also suffer from calibration and interpretation uncertainties, and more structured methods are needed for uniform interpretation.

Typical challenges of optical image processing and analysis (IPA) include inhomogeneous illumination, poor colorization differences due to porous media properties, interphase mass transfer changing the colorization, and lead to unclear fluid phase interfaces, sorption to porous media, dye degradation due to light exposure, and indirect determination of variables of interest, such as spatiotemporal NAPL saturation. In the past four decades, numerous IPA approaches have emerged in a variety of fields, (for an overview see, e.g., [43]). In some cases, generalizable IPA work flows were developed (e.g., [30,44,45]), but not for DNAPL in porous media. As a result, it is still unclear which IPA steps are required or optional for quantifying DNAPL in porous media.

The primary objective of this work is to develop a flexible and generalizable IPA framework for laboratory-scale NAPL migration studies. We performed a series of experiments to obtain raw images of DNAPL in porous media during migration and entrapment while using different dyes and three different porous media types. We used this data to evaluate a suite of IPA steps organized in a workflow. Based on a sensitivity analysis, the advantages and drawbacks of specific IPA steps are discussed and uncertainties that are related to IPA are quantified. Finally, the transferability of the IPA framework to similar laboratory setups of different focus (e.g., dissolved solute transport) is presented.

\section{Delineation of an IPA Framework for DNAPL Release Studies}

\subsection{General Considerations for Optical Imaging}

In general, any optical IPA method and its applicability depend on the properties of the experimental setup, e.g., the porous media, the fluids, and the dye. For selected semi-transparent porous media (e.g., glass beads), it is possible to use light transmission visualization to detect movements 
of phases or dissolved substances in porous media, where the light source is on the opposite side of the tank when compared to the camera (e.g., [29,30,33,45-48]). However, this approach typically requires non-opaque porous media, such as glass beads (e.g., [21,49-51]). Reflective light imaging methods (RLM) are more flexible and they can be used for both non-opaque and opaque porous media. The latter are more common, e.g., natural materials, like sands and silts, and are the focus in this work.

RLM requires the use of colorized dyes [52]. In NAPL migration studies, the non-wetting phase (i.e., DNAPL) is typically colorized. Prominent examples of relevant dyes in the visible light spectrum are Oil-Red-O, Sudan Blue, Sudan III, and Sudan IV [33-40,53,54]. Such dyes are commonly used for semi-transparent porous media, such as glass beads, due to the good contrast ratio between porous media with water and with dyed DNAPL. Adding a visible-light spectrum dye to the wetting phase, e.g., Rhodamine-B or Brilliant Blue FCF, can further enhance this contrast (e.g., [55]). For natural porous media, dyes in the infrared (e.g., [56]), ultraviolet or fluorescence spectra provide greater contrast (e.g., [28,37,57-62]). In most prior works, dye choice has been based on good visibility, low price, or similar work in the literature. However, dye properties affect the accuracy of IPA; hence, careful attention to the relevant properties is required.

Known dye properties that affect the accuracy of DNAPL experiments and IPA results are photodegradation and bleaching, sorption to porous media, wettability, density or viscosity alteration, and interphase mass transfer $[59,63]$. Photodegradation and photobleaching have been observed for several fluorescent dyes, including the commonly used fluorescein, which lead to decreasing light intensity over time, despite constant DNAPL or water saturation levels [59]. Sorption onto the porous media grains was observed for Brilliant Blue FCF [55]; the sorbed dye represents another color source that confounds image interpretation. Wettability, density, or viscosity alteration is common for a number of dyes, and can affect fluid migration and entrapment [24,64,65]. However, often such effects are small or can be quantified. Last, interphase mass transfer can result in dye depletion from the target phase over time. Dyes with high solubility in the target phase and negligible solubility in the adjacent phase are desired.

In most DNAPL migration and entrapment experiments, images are sequentially taken over time (e.g., [34,45]). Temporal fluctuations in light intensity (due to, e.g., light power supply) can make comparison of sequential images challenging, as threshold values for delineating DNAPL can change (e.g., [66]). Spatial variations in light intensity within a single image can lead to similar issues [14,30]. A related challenge is separating the regions (e.g., porous media with DNAPL) from background, even with uniform light intensity (e.g., [48]). Multi-channel images (i.e., images that consist of three individual channels such as red, green, and blue-RGB) often show low contrast due to optical noise (e.g., [49,62]). In many cases, multi-channel images must be converted to single-channel images (e.g., grayscale spectrum) and resolution is further lost. Filtering approaches can be used to minimize optical noise for contrast enhancement (e.g., [66]), but they may lead to information loss.

\subsection{Conceptualization of a Basic IPA Framework for DNAPL Release Studies}

The aforementioned issues prove that adequate image manipulation via IPA is generally required to yield reliable results, i.e., manipulated images showing the information of interest with the best accuracy and least uncertainty. The most commonly applied IPA steps that we found in the literature are given in full detail in Table A1 in the Appendix A. Based on our prior analysis, we integrated our findings and propose the IPA framework in Figure 1. Note that raw images collected in this work are in ARW format (i.e., Co. Sony-related raw image format), with a spatial image resolution of 3648 $\times 3648$ pixels (1:1 length-width ratio) in 24-bit color depth for each sRGB channel (see Section 3 for description of experimental works). We used Python [67] as the scripting language for developing the IPA framework, because many IPA approaches are available as free-to-use packages. Along with others, such as Pillow (Available online: https://python-pillow.org (last accessed on 10 September 2019)) or scikit-image (Available online: https://scikit-image.org (last accessed on 10 September 2019)), OpenCV (Available online: https://opencv.org (last accessed on 22 August 2019)) is a widely used 
package and it has been selected for this work. All scripts and a tutorial file configuration are available under http://dx.doi.org/10.25532/OPARA-39.

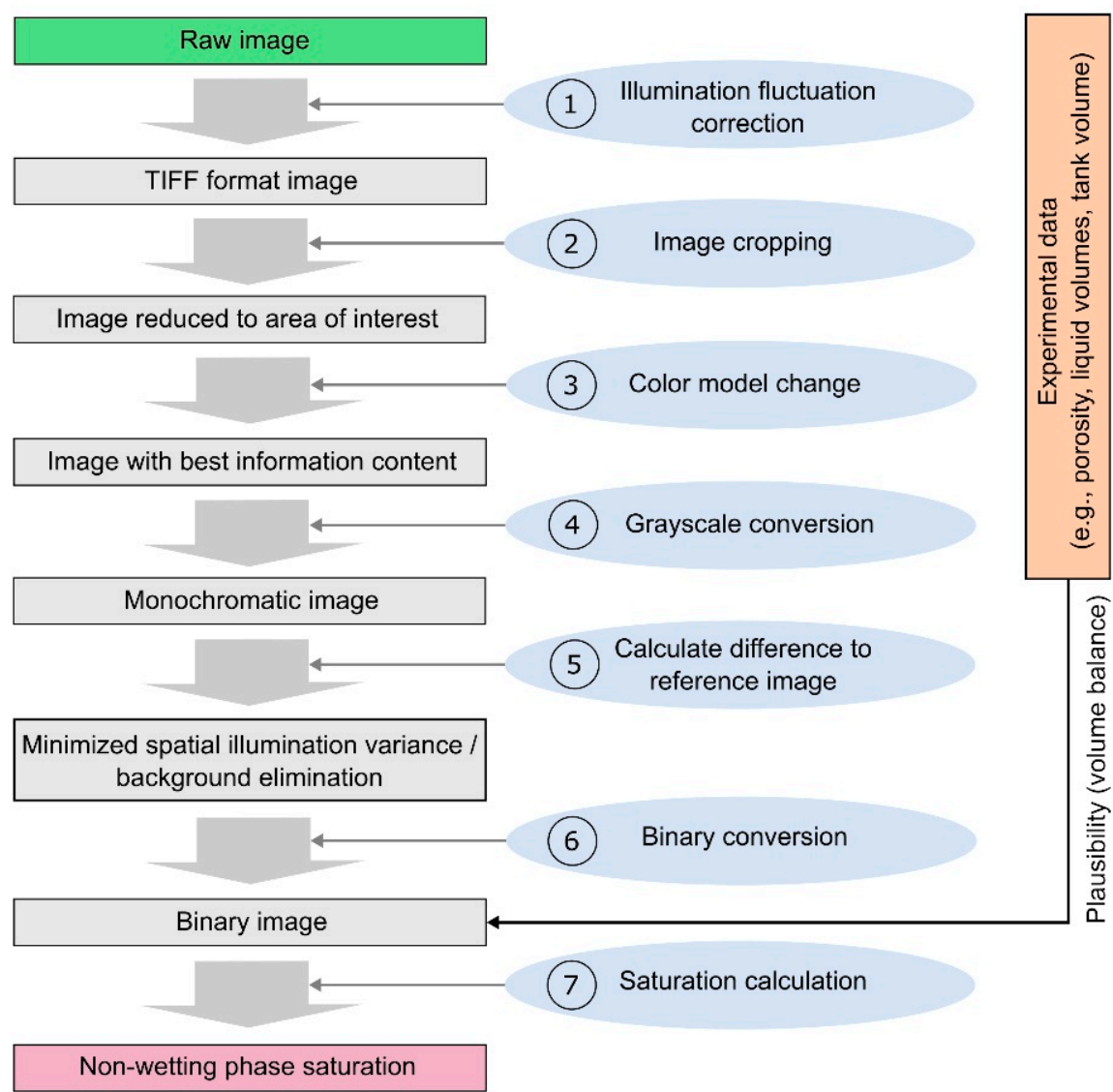

Figure 1. Proposed image processing and analysis (IPA) framework for delineating dense non-aqueous phase liquids (DNAPL) saturation distribution in tank experiments (gray boxes: aims of image enhancement; blue boxes: IPA steps; orange box: external information).

The first IPA step is to correct for temporal light fluctuations by dividing the light intensity of every pixel in a single image by the light intensity of a single or group of reference pixel(s) at a fixed location whose appearance remains constant over time (e.g., $[29,30])$. As porous media appearance can change over time, the reference pixel(s) capture light intensity on a uniform surface, like a gray photostock card placed next to the tank set-up (see Figure 2). This step was done while converting ARW images to 16-bit TIFF format using the Imaging Edge software (Co. Sony).

The second step is to crop images to exclude experimental details that are not relevant to tracking DNAPL migration and entrapment (e.g., tank frame, scales, inlet tubing). This is manually done on the first image and then automated once the desired image dimensions are known through a definition of horizontal and vertical extent (each with starting and end point).

The third IPA step is to convert images to another color model for easier delineation of the desired information (e.g., [49,68]). Different color models segregate information in different ways [42], and include the RGB model (R: red; G: green; B: blue), the HSV model (H: hue; S: saturation; V: value), and the $\mathrm{YCbCr}$ model (Y: luma component; $\mathrm{Cb}$ : blue difference; $\mathrm{Cr}$ : red difference) [69]. Depending on the experimental design (e.g., illumination conditions, porous media appearance), some color models and associated channels provide more relevant information (e.g., areas with noticeable DNAPL saturation). However, it is usually unclear which color models and channels provide the most information, so the cropped TIFF format images were converted to all three aforementioned color models in this work. 


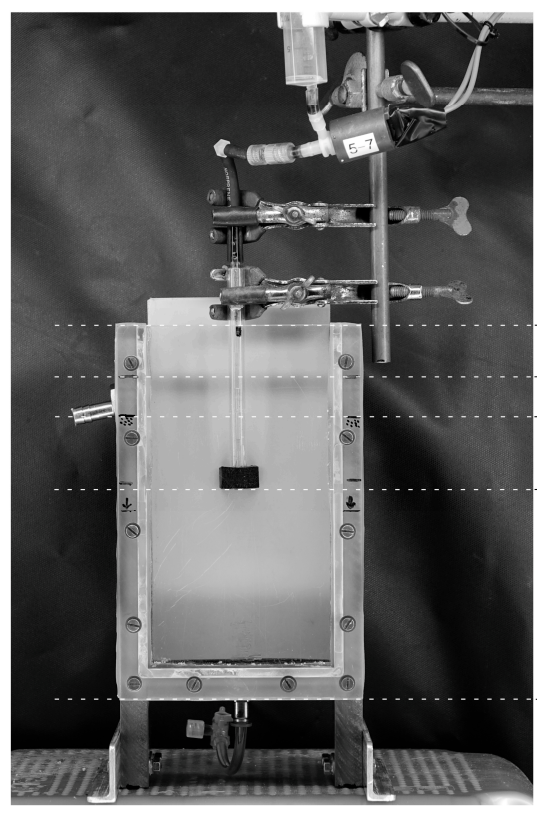

(a)

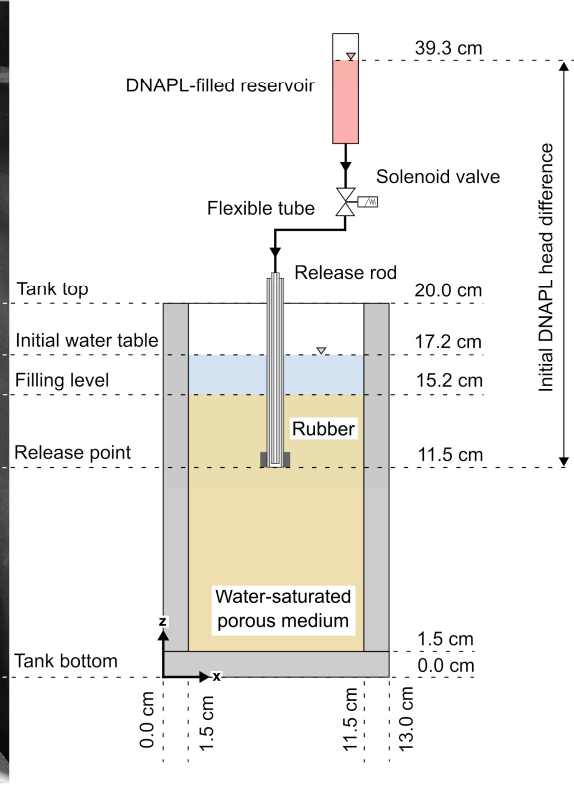

(b)

Figure 2. Experimental setup for IPA evaluation for different porous media: (a) empty tank setup (lower outlet permanently closed); (b) schematic sketch of the experimental tank (not to scale). The rubber piece prevented DNAPL upward movement and guaranteed equal release rod positioning for each DNAPL release scenario.

The fourth IPA step is to select either a single-channel image (i.e., a monochromatic or grayscale image represented as one out of three channels per color model) or convert a multi-channel image to a single monochromatic image. This allows, for example, the simplification of thresholding for conversion to binary image (e.g., [70]). The choice of which approach to use depends on what single- or multi-channel image best captures the DNAPL distribution based on visual comparison. In this study, all of the sRGB TIFF format images were converted to grayscale and directly split to all single-channel images from the three-color models noted above.

The fifth IPA step is to correct for spatial variations in light intensity and reduce background noise (e.g., $[14,30])$. The light intensity of every pixel in a reference image can be subtracted from the light intensity of every pixel at the same location in the real image to reduce spatial light variability. The reference image is taken under the same conditions (camera settings, distance, image size), but without DNAPL present. Such image subtraction can also reduce the optical noise on processed images (e.g., [48]). Alternatively, variable thresholding within a single image can be performed to eliminate spatial variations in light intensity. The latter often involves the manual thresholding of several initial images, and the same approach can then be applied automatically to subsequent images. Optical noise can also be reduced using advanced mathematical algorithms (e.g., [71,72]). However, for NAPL-related investigations, this may cause information loss, especially for image areas with residual NAPL volumes (e.g., ganglia or blobs). Therefore, only image subtraction was used in this work.

The sixth IPA step is to convert monochromatic light adjusted images to binary images for DNAPL quantification. For this, Otsu's method [73], triangle thresholding, adaptive mean, and Gaussian thresholding (each with $3 \times 3,5 \times 5,7 \times 7,9 \times 9$, and $11 \times 11$ neighbor pixels), as well as manual threshold selection were applied. For the latter one, several local minima of pixel frequency within the grayscale spectrum are calculated and the threshold providing the best fitness criterion (see Section 3.3) was selected. Details regarding binary conversion algorithms are available from, e.g., [43] or the OpenCV documentation. 
The seventh and last IPA step is to subdivide each image into a regular grid of $\sim 60,00015 \times 15$ pixel groups, which represents a pore size of $\sim 1 \mathrm{~mm}^{2}$ according to the single-size fractions that were used in this work (see Sections 3.1 and 3.2). The ratio of white to total pixels in each $15 \times 15$ pixel group is calculated, ranging from 0 to 1 . Zero indicates no DNAPL presence and one indicates that all pore space is filled with DNAPL. Intermediate values are assumed to linearly scale with DNAPL saturation [34]. The final result yields the spatial distribution of DNAPL saturation for each serial image time step.

\section{Experimental Investigations for IPA Framework Evaluation}

We performed DNAPL release experiments in a transparent tank, each with a different set of dye(s) and porous media type in order to evaluate the proposed IPA framework. Detailed methods are described below.

\subsection{Fluids, Porous Media and Dyes}

Distilled water was degassed to avoid air entrapment and adjusted to $\mathrm{pH} 8.0$ by adding $0.1 \mathrm{M}$ sodium hydroxide $(\mathrm{NaOH})$; this minimized the adsorption of aqueous phase dyes to the porous media [74]. Hydrofluoroether (HFE-7100, $>99 \%$, Co. $3 \mathrm{M}^{\mathrm{TM}}$ Novec $^{\mathrm{TM}}$ ) was used as the DNAPL. This engineered, non-toxic liquid has density, viscosity, and interfacial properties similar to tetra- or trichloroethylene, common DNAPLs at hazardous waste sites $[34,75]$. The addition of methyl octanoate ( $>98 \%$, Co. Thermo Fisher Scientific) allowed for dying the non-wetting phase, yielding a mixture density of $1.48 \times 10^{3} \mathrm{~kg} / \mathrm{m}^{3}$ and a viscosity of $0.6 \times 10^{-3} \mathrm{~Pa} \mathrm{~s}$ at $20^{\circ} \mathrm{C}$ according to [34]. The HFE-7100 has a very low solubility in water (i.e., $<12 \mathrm{mg} / \mathrm{L}$ ), which prevented it from appreciably dissolving during the experimental time frame ( two hours).

Three different types of porous media, ranging from semi-transparent to opaque, are tested to evaluate the need for semi-transparent materials for successful IPA. These are clear glass beads (diameter $1 \mathrm{~mm}$, Co. VWR), filtering glass (0.8-1.2 mm diameter, cracked glass with irregular grain shape, Co. Nature Works), and poorly-graded natural sand with a small fraction of fines (highly irregular and non-uniform, obtained from a sand pit in Pirna, Saxony, Germany). The filtering glass and the natural sand were dry sieved to a single-size fraction between 1.0 to $2.0 \mathrm{~mm}$. After sieving, these materials were washed and oven-dried for $24 \mathrm{~h}$ at $105^{\circ} \mathrm{C}$. Each porous medium was characterized for hydraulic properties (see Table 1$)$. Hydraulic conductivity $K_{s}(\mathrm{~m} / \mathrm{s})$ was estimated while using a permeameter with constant head $\left(\mathrm{K}_{\mathrm{SAT}^{\mathrm{TM}}}{ }^{\mathrm{T}}, \mathrm{Co}\right.$. Meter). Porous media were deposited in the permeameter and tank (see Figure 2 in Section 3.2) in the same way to achieve similar compaction. This was done by the underwater filling of $\sim 1 \mathrm{~cm}$ sediment layers analogous to [74] and, subsequently, rubber hammer sledging against the outer tank walls. Porosity, $n$, was estimated while using the standard volumetric method. Bulk density $\rho_{b}\left(\mathrm{~kg} / \mathrm{m}^{3}\right)$ and grain density $\rho_{s}\left(\mathrm{~kg} / \mathrm{m}^{3}\right)$ were determined by gravimetric analysis using the known porosity $n(-)$. Two repetitions were used for each hydraulic test to evaluate precision.

Table 1. Hydraulic characteristics for each porous media type, determined at room temperature $\left(\sim 22.5^{\circ} \mathrm{C}\right)$.

\begin{tabular}{|c|c|c|c|c|c|c|c|c|c|}
\hline \multirow{2}{*}{$\begin{array}{c}\text { Variables } \\
\text { Trial Number }\end{array}$} & \multicolumn{3}{|c|}{$\begin{array}{l}\text { Glass Beads (G) } \\
\quad(1 \mathrm{~mm})\end{array}$} & \multicolumn{3}{|c|}{$\begin{array}{l}\text { Filtering Glass }(F) \\
(1 \ldots 2 \mathrm{~mm})\end{array}$} & \multicolumn{3}{|c|}{$\begin{array}{l}\text { Natural Sand (S) } \\
(1 \ldots 2 \mathrm{~mm})\end{array}$} \\
\hline & 1 & 2 & 3 & 1 & 2 & 3 & 1 & 2 & 3 \\
\hline $\begin{array}{l}\text { Fully water-saturated hydraulic } \\
\text { conductivity } K_{s}\left(\times 10^{-3} \mathrm{~m} / \mathrm{s}\right)\end{array}$ & 6.13 & 6.26 & 5.81 & 8.75 & 7.53 & 6.87 & 3.17 & 4.41 & 2.89 \\
\hline Porosity $n(-)$ & 0.393 & 0.401 & 0.391 & 0.445 & 0.435 & 0.436 & 0.371 & 0.381 & 0.359 \\
\hline Bulk density $\rho_{b}\left(\times 10^{3} \mathrm{~kg} / \mathrm{m}^{3}\right)$ & 1.59 & 1.51 & 1.51 & 1.36 & 1.39 & 1.40 & 1.58 & 1.59 & 1.61 \\
\hline Grain density $\rho_{s}\left(\times 10^{3} \mathrm{~kg} / \mathrm{m}^{3}\right)$ & 2.47 & 2.52 & 2.48 & 2.45 & 2.46 & 2.48 & 2.51 & 2.57 & 2.51 \\
\hline
\end{tabular}


Nine different dyes were selected for initial evaluation, and a subset of these was used in DNAPL release experiments. All of the dyes are colored in the visible light spectrum for ease of experimentation. Some dissolve in water and some in DNAPL. For evaluation, different dye combinations (see Table 2) were initially added to $100 \mathrm{~mL}$ volumes of water or HFE-7100 in bottles, and then stored overnight at $10^{\circ} \mathrm{C} \pm 1 \mathrm{~K}$ without light exposure. For every scenario, $20 \mathrm{~mL}$ glass vials were filled with $8 \mathrm{~mL}$ dyed phase(s) and three different porous media. Twenty different dye configurations were evaluated in total (see Tables 2 and A2 in the Appendix A). All of the vials were shaken for two hours before image acquisition while using a horizontal shaker (Standard Analog Shaker, Co. VWR). Finally, images of the vials were acquired every $1 \mathrm{~min}$. over $24 \mathrm{~h}$ to judge the temporal stability (e.g., photo-degradation by UV light, sorption onto porous media). The images were acquired under constant temperature and uniform light conditions (see Section 3.2).

Table 2. Dyes and their preparation to yield a volume of $100 \mathrm{~mL}$ for each dye configuration.

\begin{tabular}{ccc}
\hline Dye & Manufacturer & Amount \\
\hline Indigo carmine $^{1}$ & Co. Sigma-Aldrich GmbH & $2 \mathrm{mg}$ \\
Brilliant Blue FCF $^{1}$ & Co. Supelco ${ }^{\mathrm{TM}}$ Analytical & $5 \mathrm{mg}$ \\
Rhodamine-B $^{1}$ & Co. Sigma-Aldrich GmbH & $5 \mathrm{mg}$ \\
Red pen ink (4001 TP/6 Pink) $^{1}$ & Co. Pelikan & $1.0 \mathrm{~mL}$ \\
Blue pen ink (4001 TP/6 Royal blue) $^{1}$ & Co. Pelikan & $1.0 \mathrm{~mL}$ \\
Green pen ink (4001 TP/6 Dark green) $^{1}$ & Co. Pelikan & $0.5 \mathrm{~mL}$ \\
Oil-Red-O (dissolved in 0.5\% propylene glycol) $^{2}$ & Co. Sigma-Aldrich GmbH & $4 \mathrm{~mL}$ \\
Sudan IV $^{2}$ & Co. Alfa Aesar & $5 \mathrm{mg}$ \\
Sudan Blue $^{2}$ & Co. abcr GmbH & $10 \mathrm{mg}$ \\
\hline
\end{tabular}

${ }^{1}$ mixed with $100 \mathrm{~mL}$ distilled, degassed water at $\mathrm{pH} 8.0 ;{ }^{2}$ mixed with $4 \mathrm{~mL}$ methyl octanoate $(>98 \%$, Co. Thermo Fisher Scientific) and 96 mL HFE-7100.

\subsection{Tank Setup for Investigating DNAPL Release in Different Porous Media}

A small-scale tank with an inner volume of $0.185 \times 0.1 \times 0.03 \mathrm{~m}^{3}$ was used to generate raw data for IPA evaluation (see Figure 1). Although three-dimensional effects cannot be avoided, the tank's thickness allows for quasi-two-dimensional migration in $\mathrm{x}-\mathrm{z}$ direction with the chosen porous media. According to [55,74], the tank thickness shall be at least sixteen times the largest grain size. The front panel is made of polymethyl methacrylate (i.e., acrylic glass), while all other panels are polyvinyl chloride material. The tank was placed on a horizontally aligned frame. The entire setup was run in a dark climate chamber (Co. Viessmann) at a constant temperature of $10{ }^{\circ} \mathrm{C} \pm 1 \mathrm{~K}$ to minimize the alternating environmental conditions. A rectangular aluminum frame of approx. $0.7 \times 0.7 \mathrm{~m}^{2}$ (measured in frame center) held four light-emitting diode (LED) panels with a power consumption of $18 \mathrm{~W}$ and a luminous flux of $1500 \mathrm{~lm}$ (Co. Osram), equipped with a light diffusor. The orthogonal distance between tank and LEDs was adjusted to $0.3 \mathrm{~m}$.

DNAPL release was realized with a remotely controlled solenoid valve (custom-made software). A cylindrical reservoir stored the DNAPL volume before release. This reservoir was connected to a double tube (inner diameters $2 \mathrm{~mm}$ and $6 \mathrm{~mm}$, respectively) to avoid air entrapment in the porous media. The release was maintained as a falling pressure head difference to overcome the DNAPL's entry pressure of the initially water-saturated porous media, with a starting head difference of $27.8 \mathrm{~cm}$ (equal to 4036 Pa pressure difference for a density of $1.48 \times 10^{3} \mathrm{~kg} / \mathrm{m}^{3}$ ). For each release experiment, a volume of $20 \mathrm{~mL}$ was continuously injected, representing between $\sim 15 \%$ and $\sim 18 \%$ of the porous media pore volumes (see Table 1). This release volume led to a water table rise of $\sim 3 \mathrm{~mm}$. In sum, sixteen different DNAPL release scenarios showing conservative behavior were run (Table 3; see also Section 4.1 as well as Table A2 in the Appendix A for all scenarios). 
Table 3. DNAPL release scenarios (see also Table 2 for dye preparation procedure). The scenarios are distinguished into dye configuration (A: dual color; B: water color; C: DNAPL color) and porous media type (G: glass beads; F: filtering glass; S: natural sand).

\begin{tabular}{cccccc}
\hline \multirow{2}{*}{ Scenario Class } & \multicolumn{3}{c}{ Porous Medium } & \multicolumn{2}{c}{ Dye Configuration } \\
\cline { 2 - 6 } & $\begin{array}{c}\text { Glass Beads } \\
\text { (G) }\end{array}$ & $\begin{array}{c}\text { Filtering } \\
\text { Glass (F) }\end{array}$ & $\begin{array}{c}\text { Natural Sand } \\
\text { (S) }\end{array}$ & $\begin{array}{c}\text { DNAPL } \\
\text { Phase }\end{array}$ & $\begin{array}{c}\text { Aqueous } \\
\text { Phase }\end{array}$ \\
\hline \multirow{3}{*}{ Dual color } & A2_G & A2_F & - & Sudan IV & Indigo carmine \\
& A4_G & A4_F & A4_S & Sudan IV & Brilliant Blue FCF \\
& A10_G & A10_F & A10_S & Sudan IV & Green pen ink \\
\hline \multirow{2}{*}{ Water color } & B1_G & B1_F & - & - & Indigo carmine \\
& B6_G & B6_F & B6_S & - & Green pen ink \\
\hline DNAPL color & C2_G & C2_F & C2_S & Sudan IV & - \\
\hline
\end{tabular}

Digital images were acquired while using a RX-10M2 camera (Co. Sony), equipped with a 24-200 mm F2.8 zoom lens (Vario-Sonnar T, Co. Zeiss ${ }^{\circledR}{ }^{\circledR}$ ). The camera was fixed onto a horizontally aligned tripod opposite of the tank center with an orthogonal camera-tank distance of $\sim 1.63 \mathrm{~m}$. A gray photostock card was placed next to the tank for subsequent white balance adjustment. A fully manual camera mode was defined, with equal settings for each DNAPL release scenario (lens aperture $\mathrm{f} / 4.0$, ISO 100, shutter speed 1/40 s, hard manual focus with center-weighted pattern, focal length $200 \mathrm{~mm}$, and serial image time step length of $10 \mathrm{~s}$ ). All of the unprocessed raw TIFF format images used for IPA framework evaluation are presented in the Electronic Supplementary Material (ESM) S1.

\subsection{Measures for IPA Framework Evaluation}

A large number of different IPA scenarios (i.e., different IPA step combinations defining the workflow from raw to binary images) was applied to all DNAPL release scenarios (see Table 3). $T$ delineate the performance of each IPA scenario, the fitness of each final binary image was calculated based on the volume balance

$$
V_{b a l}=\frac{V_{D N A P L}}{n \times V_{t o t}}
$$

with DNAPL release volume $V_{D N A P L}\left(\mathrm{~m}^{3}\right)$ and inner tank volume below DNAPL release location $V_{\text {tot }}$ $\left(\mathrm{m}^{3}\right)$. The validity of Equation (1) assumes negligible three-dimensional (3-D) effects (i.e., uniform DNAPL migration $y$ direction). Values of $V_{b a l}(-)$ were then compared to the white-black pixel ratio WBPR (-) of binary images. This provides information regarding the DNAPL coverage area (white pixels) as compared to the area filled with water (black pixels). For example, with a $V_{\text {tot }}$ of $300 \mathrm{~mL}$ (see Figure 2), a $V_{D N A P L}$ of $20 \mathrm{~mL}$ and $n$ values according to Table 1, the $W B P R$ values should ideally be 0.169 for glass beads, 0.152 for filtering glass, and 0.180 for natural sand. The quality criterion

$$
Q C=\frac{W B P R}{V_{b a l}}
$$

was then calculated. Hereby, WBPR values were calculated while considering all IPA steps except difference calculation to the reference image (IPA step 3, i.e., correction for spatially non-uniform illumination and background exclusion; see Figure 1). The quality criterion

$$
Q C_{\text {diff }}=\frac{W B P R_{\text {diff }}}{V_{\text {bal }}}
$$

was calculated using $W B P R_{\text {diff }}$ values that consider all IPA steps, including difference calculation to reference images. The best fit is given if the quality criteria become 1 . Values above 1 indicate DNAPL 
volume overestimation, and vice versa. For determining the relevance of light fluctuation correction (IPA step 1; see Figure 1), values of

$$
\overline{Q C_{\text {diff }}}=\frac{1}{n} \sum_{i=1}^{n} Q C_{\text {diff }, i}
$$

were calculated, with image number $i$ ranging between 1 (begin of the spill event) and the last image of investigation $n$. This served as a measure for identifying the optimized IPA configurations for each of the sixteen DNAPL release scenarios (see Section 4.2.1).

\section{Results and Discussion}

\subsection{Evaluation of Dye Configurations and their Suitability for DNAPL Release Studies}

Different dye configurations (see Section 3.1) have been tested to judge their suitability for DNAPL release studies that were evaluated by optical imaging. Out of 60 selected configurations, 44 dye configurations could be excluded, because at least one criterion was not met (see Table A2 in the Appendix A). The remaining sixteen dye configurations (see Table 3) were used for running the DNAPL release scenarios and they formed the base for IPA framework evaluation (see Section 3.3). Within the times scales of the batch scenarios $(24 \mathrm{~h})$, we could not observe any blurring of the transition zones between the two phases.

\subsection{Delineation of Uncertainties related to Individual IPA Framework Steps Applied to Experimental DNAPL Release Scenarios}

Selected results of the DNAPL release scenarios (see Table 3) are given below. The unprocessed raw TIFF format images are presented in ESM S1. Individual IPA steps (see Figure 1) were evaluated to estimate their relevance within the framework. Associated uncertainties that are related to IPA configuration were quantified. The results not presented here are shown in ESM S2 and S3. Note that the order of subsections does not correlate with the IPA framework workflow order.

\subsubsection{Correction of Temporal Illumination Fluctuation}

First, $Q C_{\text {diff }}$ values based on the Equations (1) and (3) were determined for each time step. This was done while considering the optimal combination of single channel and binary conversion algorithm for each dye configuration scenario, excluding the adaptive Gaussian and mean binary conversion algorithms due to optical noise (see next two sections). Here, the values were calculated for the IPA configuration with and without white balance adjustment (IPA step 1; see Section 2.2). Subsequently, for each IPA configuration, $\overline{Q C_{d i f f}}$ values were calculated after Equation (4) to identify the optimized IPA configuration for each of the sixteen DNAPL release scenarios. The optimal IPA configuration was then used to evaluate time series of $Q C_{\text {diff }}$ (see Figure 3). It can be seen that the $Q C_{\text {diff }}$ values mainly vary between 0.5 and 1.5 for glass beads and natural sand within the first $250 \mathrm{~s}$ after DNAPL release (see Figure 3). A larger variation occurs for filtering glass, with $Q C_{\text {diff }}$ values between 0 (no DNAPL detected) and 3 (represent $200 \%$ overestimation of DNAPL volume). Generally, the fitness of most DNAPL release scenarios is better if the white balance adjustment is applied. The A4 and A10 scenarios show the best fitness among all other scenarios, which indicates the benefit of dying both the DNAPL and aqueous phase. However, no statement is possible as to whether it is more advantageous for this IPA step to use aqueous phase dyes instead of DNAPL phase dyes, or vice versa. 


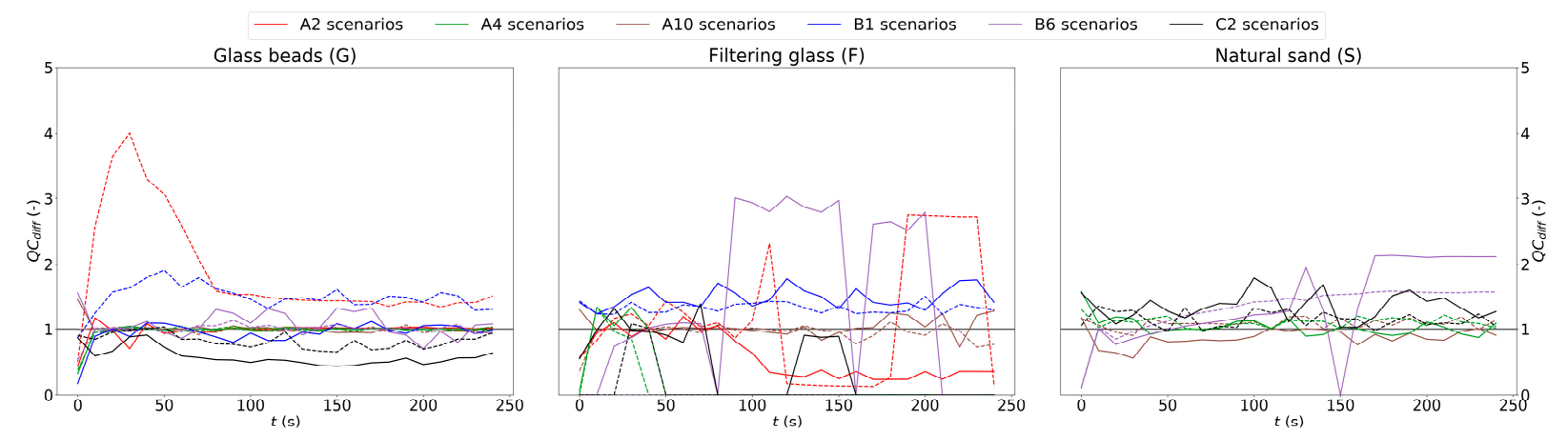

Figure 3. Relevance of temporal illumination fluctuation correction through white-balance adjustment. Shown is the time series of $Q C_{\text {diff }}$ values as measure for IPA verification (solid lines: with white balance adjustment; dotted lines: without white balance adjustment) considering the optimal IPA framework configuration for each dye configuration and porous media type, respectively. See Table 3 for a key to the legend (e.g., A2 scenarios).

\subsubsection{Color Model Change and Binary Conversion Algorithms}

In this section, the relevance of different single-channel images (IPA step 3) and their performance are presented. Depending on dye configuration and porous media type, large differences in DNAPL source zone coverage were identified. For all porous media, the straightforward conversion from sRGB to grayscale leads to implausible results, with $Q C_{\text {diff }}$ values far below 1 (i.e., SZG not separated from background; see ESM S2). In contrast, some single channels clearly show overestimations of the source zone volume. For glass beads, filtering glass and natural sand, overestimations up to $265 \%$ (see Figure S2.28 in ESM S2), 333\% (see Figure S2.58 in ESM S2), and 280\% (see Figure S2.76 in ESM S2) were observed, respectively.

Figure 4 presents the best IPA framework configurations with respect to each porous media type. For glass beads, the $S$ channel (of the HSV model) led to a $Q C_{\text {diff }}$ value of 1.0053, whereas other channels that are able to separate the SZG show $Q C_{\text {diff }}$ values ranging from 0.9932 to 1.6106. For filtering glass, only the $S$ channel with a $Q C_{\text {diff }}$ value of 1.0151 could identify the SZG. For natural sand, the best fit with a $Q C_{\text {diff }}$ value of 1.0839 was achieved while using the $\mathrm{Cr}$ channel (of the $\mathrm{YCbCr}$ model). The $\mathrm{H}$ and $\mathrm{Cb}$ channels could also identify the $\mathrm{SZG}$, however $Q C_{\text {diff }}$ values up to 2.5446 indicate source zone overestimation.

Although the binary conversion algorithms adaptive Gaussian and mean mainly show $Q C_{\text {diff }}$ values close to 1, all binary images were not able to separate the SZG from the background due to optical noise (see Figure 4 and ESM 2). The remaining algorithms (manual threshold with best fitness, Otsu's method, triangle) produced much less optical noise. Depending on the selected channel, Otsu's method and the triangle algorithm lead to significant over- and underestimation, with more extremes for the latter one. Overall, the manual threshold method shows the best fitness for all porous media types. 

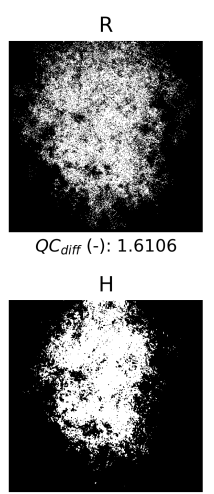

$Q C_{\text {diff }}(-): 1.5374$

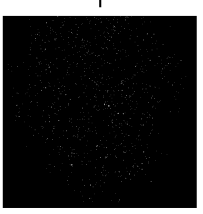

$Q C_{\text {diff }}(-): 0.0238$

orig_gray

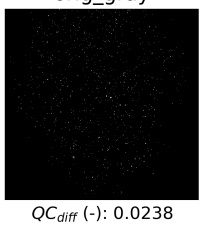

G
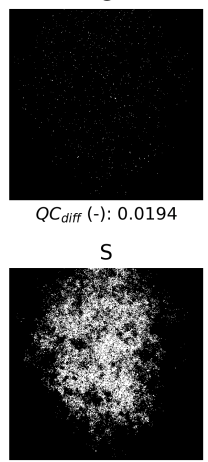

$Q C_{\text {diff (-): } 1.0053}$

$\mathrm{Cr}$

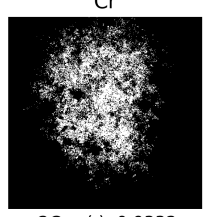

$Q C_{\text {diff }}(-): 0.9332$
B

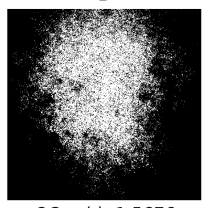

$\mathrm{V}$

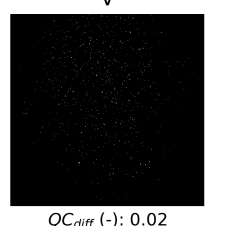

$\mathrm{Cb}$

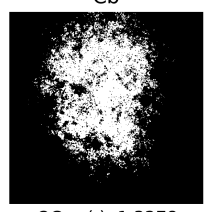

$Q C_{\text {diff }}(-): 1.3278$

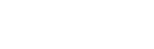

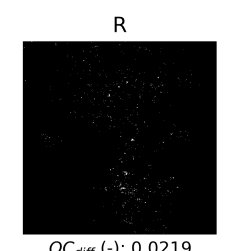

$Q C_{\text {diff }}(-): 0.0219$

$\mathrm{H}$

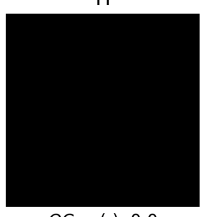

$Q C_{\text {diff }}(-): 0.0$

$Y$

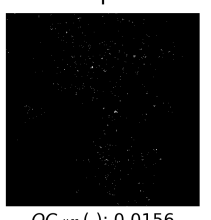

$O C_{\text {diff }}(-): 0.0156$

orig_gray

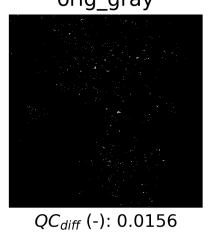

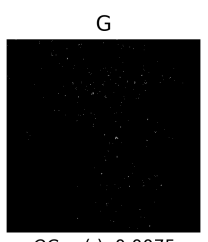

$\mathrm{S}$

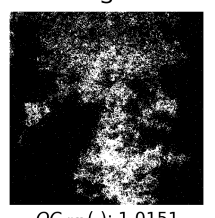

$Q C_{\text {diff }}(-): 1.0151$

$\mathrm{Cr}$

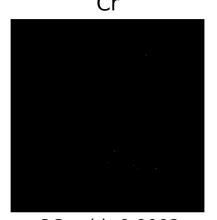

$Q C_{\text {diff }}(-): 0.0002$

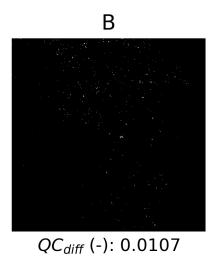

$\mathrm{V}$

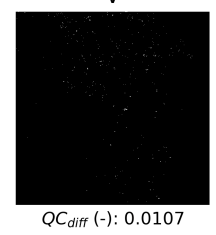

$\mathrm{Cb}$

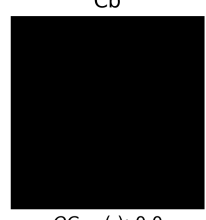

(b)

(a)
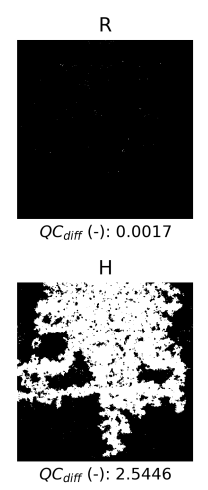

$\mathrm{Y}$

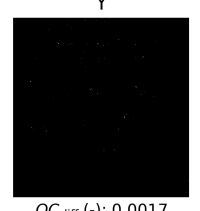

orig_gray

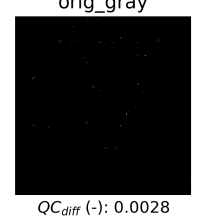

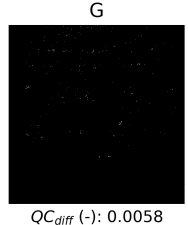

$\mathrm{S}$

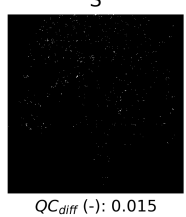

$\mathrm{Cr}$

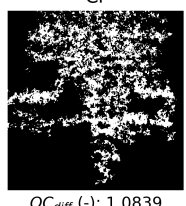

$Q C_{\text {diff }}(-): 1.0839$

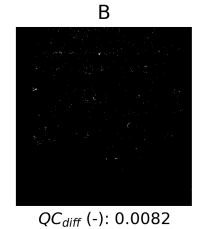

$\mathrm{V}$

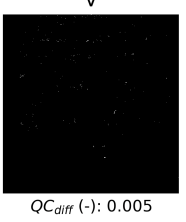

$\mathrm{Cb}$

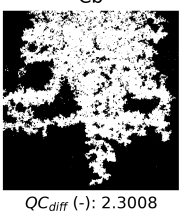

(c)

Figure 4. Comparison of different single channels of the three color models red, green, and blue (RGB), HSV (H: hue; S: saturation; V: value), and YCbCr (Y: luma component; $\mathrm{Cb}$ : blue difference; $\mathrm{Cr}$ : red difference), as well as via straightforward conversion sRGB to grayscale for the DNAPL release scenarios (a) A4_G ( $(=30 \mathrm{~s}),(\mathbf{b})$ A10_F $(\mathrm{t}=80 \mathrm{~s})$, and (c) B6_S ( $\mathrm{t}=90 \mathrm{~s})$. Binary images under consideration of all IPA steps are shown, whereby manual thresholds leading to best fitness criterion $Q C_{\text {diff }}$ value was selected as the binary conversion method. 


\subsubsection{Correction of Spatially Non-Uniform Illumination and Background Exclusion}

For evaluating the relevance of correcting for spatially non-uniform illumination (IPA step 5), which might also contribute to better background exclusion, difference images between corrected and uncorrected binary images were evaluated by comparing the $Q C$ values to $Q C_{\text {diff }}$ values calculated by the Equations (2) and (3), respectively (see Figure 5 for an example; the remaining scenarios can be found in ESM S3). As already identified in Section 4.2.2, all the images resulting from adaptive Gaussian and mean binary algorithms show implausible results with elevated optical noise, and the difference between corrected and uncorrected binary images is comparably low. For the remaining binary conversion algorithms, depending on the selected single channel, differences mainly occur either in the vicinity of tank walls (indicating illumination correction; see, e.g., Figure $5 \mathrm{~b}$ for Otsu's method) or within the source zone itself (indicating background exclusion; see, e.g., Figure 5a for manual threshold). In most cases and mostly independent from the dye configuration, the $Q C_{\text {diff }}$ values are closer to 1 when compared to $Q C$ values. This supports the importance of incorporating difference images as IPA step.

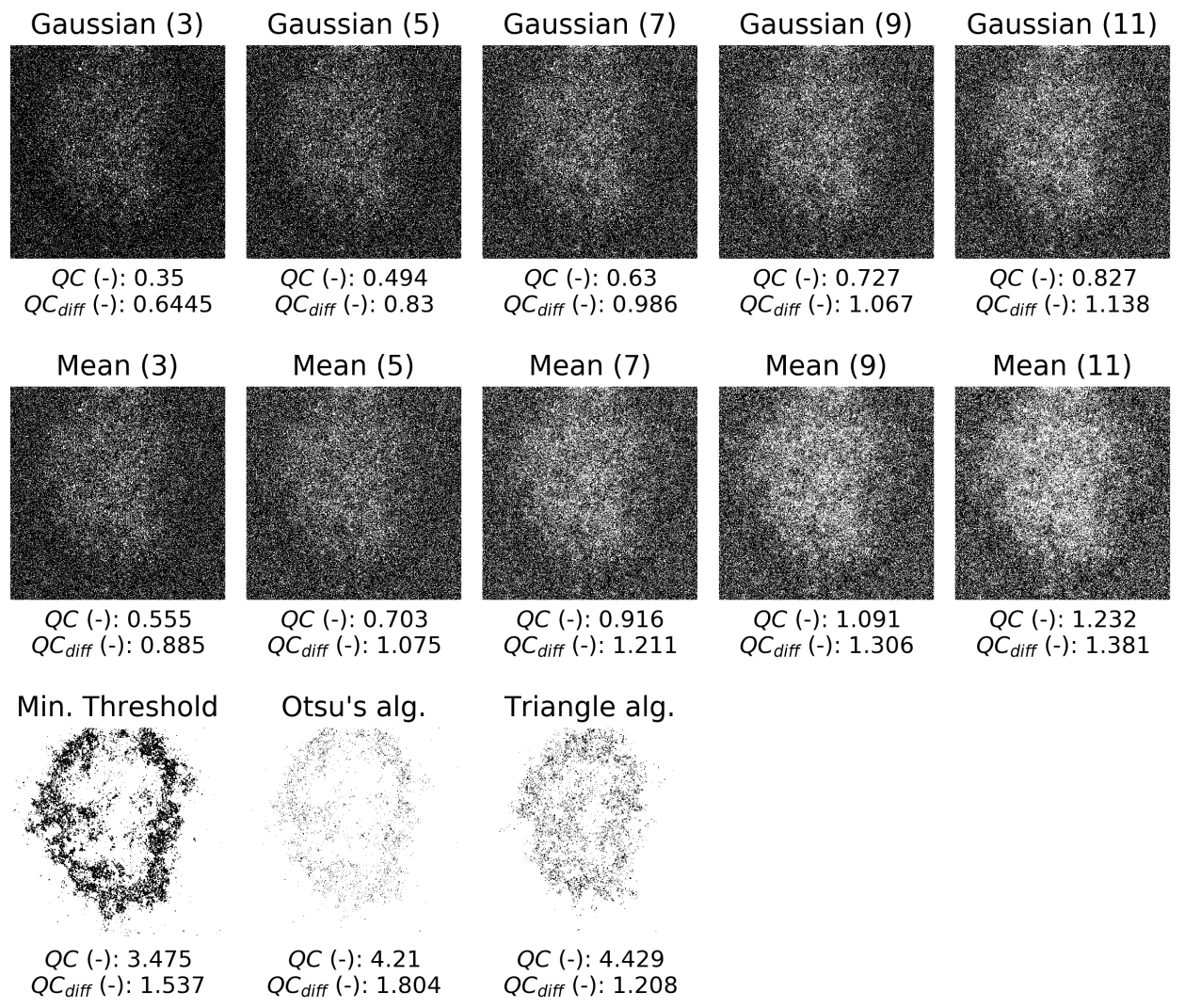

(a)

Figure 5. Cont. 


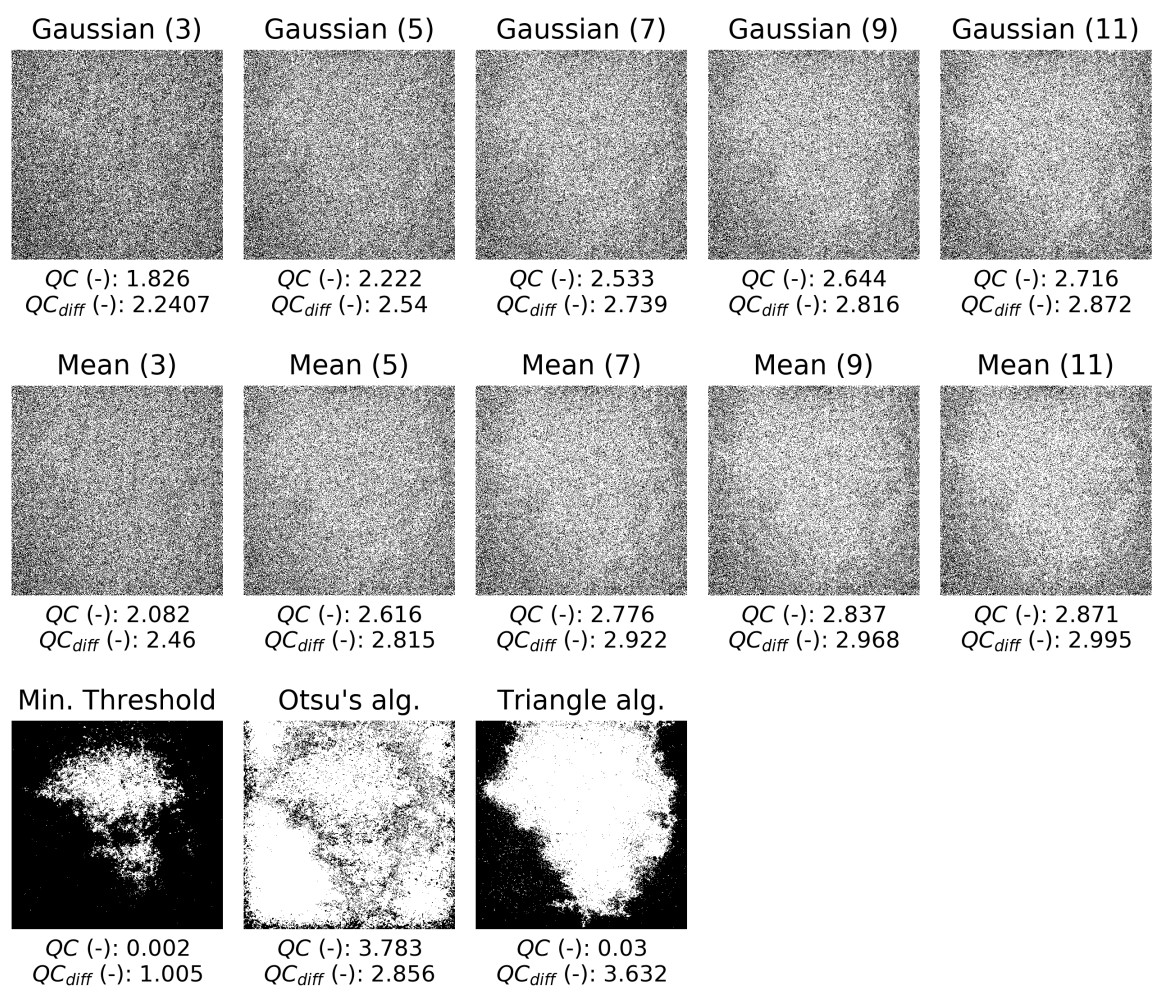

(b)

Figure 5. Relevance of non-uniform illumination correction and background exclusion. The differences between correction method application (i.e., calculation of image difference between time step and reference image before DNAPL release) and uncorrected images for the DNAPL release scenarios (a) A4_G ( $\mathrm{t}=30 \mathrm{~s} ; \mathrm{H}$ channel) and (b) A4_F ( $\mathrm{t}=50 \mathrm{~s}$; G channel) under consideration of all other IPA steps (see Figure 1) are shown. Numbers in parentheses behind the adaptive Gaussian and mean binary conversion algorithms are the amount of neighbor pixels.

\subsubsection{Delineation of Optimized IPA Framework Configuration for each Porous Media Type}

Figure 6 shows the performance of all dye and IPA framework configurations. The performance clearly depends on porous media types (rows in Figure 6), the dye configuration (columns in Figure 6), the binary conversion algorithm, and the selected single channel. It can be seen that the $Q C_{\text {diff }}$ values are generally in the vicinity of the optimal value 1 for all adaptive Gaussian and median binary conversion algorithms. However, as already shown in Sections 4.2.2 and 4.2.3 (see also ESMs S2 and S3), these algorithms largely suffer from optical noise and they produce implausible results. The binary conversion algorithms manual threshold (local minimum with best fitness) and Otsu's method lead to best fitness in most cases, whereby the performance of the first one depends highly on the single channel being selected. For glass beads, the best $Q C_{\text {diff }}$ values are between 0.8825 and $1.0131(-11.75 \%$ to $1.31 \%)$. For filtering glass, the range is between 0.9715 and 1.4137 ( $-2.85 \%$ to $41.37 \%)$, and for natural sand between 0.8880 and $1.3964(-11.2 \%$ to $39.64 \%)$. Based on these findings, the optimized dye and IPA framework configuration could be identified for each porous medium (glass beads: A4_G, S channel, manual threshold with best fitness; filtering glass: A10_F, S channel, manual threshold with best fitness; natural sand: B6_S, Cr channel, manual threshold with best fitness). These configurations were then used for calculating the spatial distributions of DNAPL saturation $S_{n w}$ for selected time steps (see Section 4.2.5). 


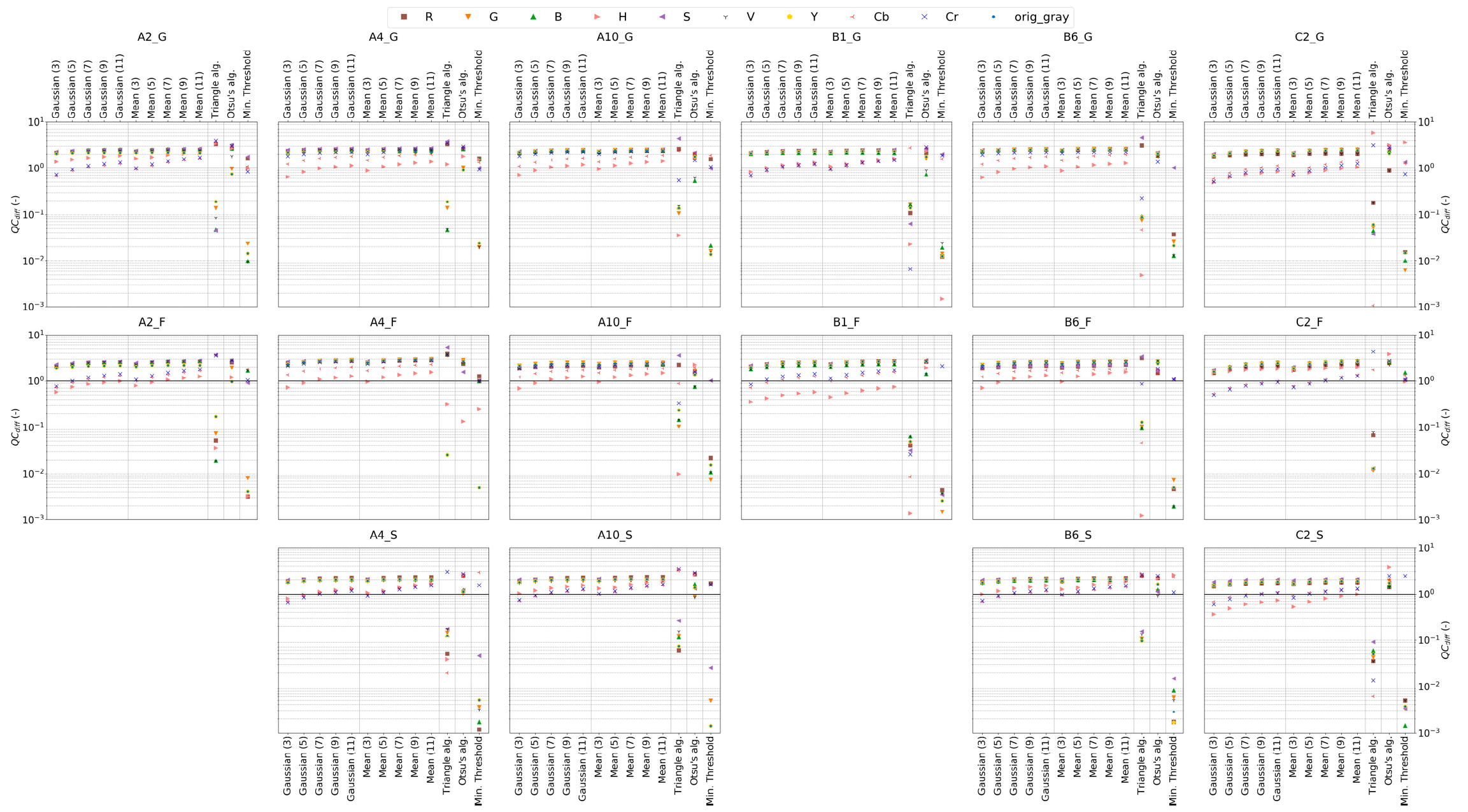

Figure 6. Evaluation of optimal IPA framework configuration for all sixteen DNAPL release scenarios $(t=[30,50,90] \mathrm{s}$ for glass beads, filtering glass and natural sand, respectively; see Table 3). $Q C_{\text {diff }}$ values depending on the ten single channel images and thirteen binary conversion algorithms are shown, whereby values near 1 indicate good fitness. 


\subsubsection{Calculation of DNAPL Saturation and Comparison for the three Porous Media Types}

With respect to all previous IPA framework evaluations (see Sections 4.2.1-4.2.4), it was possible to identify both the optimal dye and the IPA framework configuration for all three types of porous media used. Subsequently, DNAPL saturation $S_{n w}(-)$ values were calculated for all experimental time steps (IPA step 7). Uncertainties were quantified, with $0.5 \%$ for glass beads, $1.5 \%$ for filtering glass, and $8.4 \%$ for natural sand. The transient DNAPL migration and entrapment behavior can clearly be distinguished into three stages (see Figure 7). During the spill event, the DNAPL distribution forms a sphere-like shape due to increasing capillary pressure beneath the release rod $(t=20 \mathrm{~s})$. Once the spill event has ceased, the DNAPL starts its downward migration primarily induced due to gravity force $(t=60 \mathrm{~s})$. Finally, the pooling process starts after hitting the bottom of the tank setup $(t=100 \mathrm{~s})$.

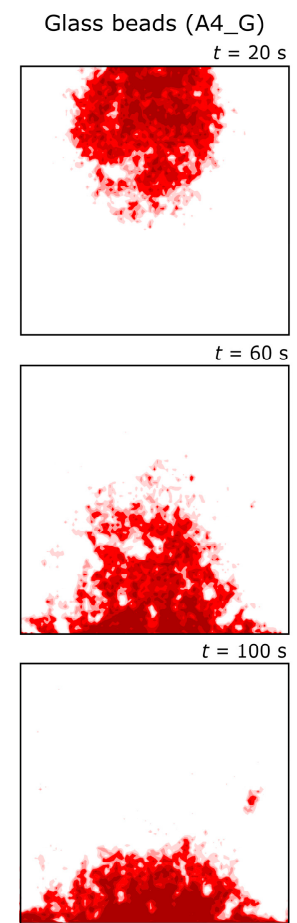

(a)

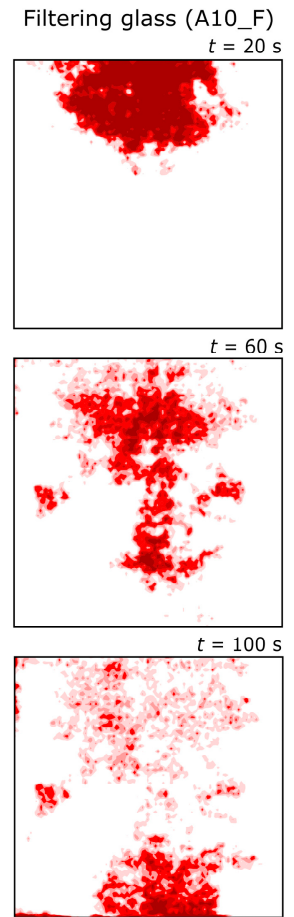

(b)

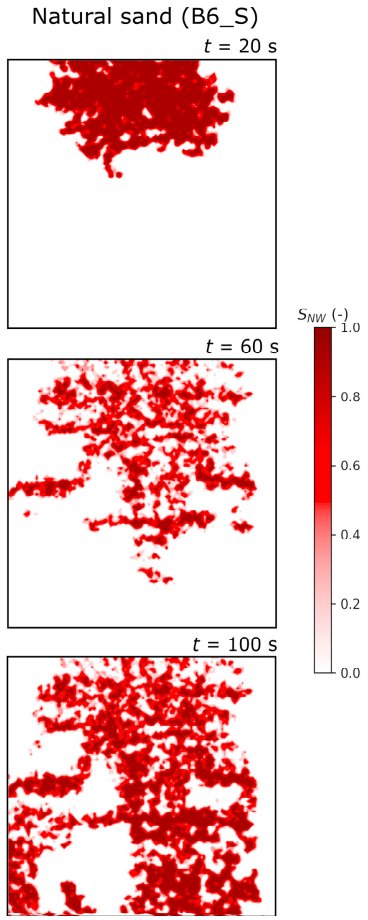

(c)

Figure 7. Calculated spatial distributions of DNAPL saturation $S_{n w}(-)$ for DNAPL release into the $0.1 \times$ $0.1 \times 0.03 \mathrm{~m}^{3}$ tank using (a) glass beads (scenario A4_G; S channel, manual threshold with best fitness), (b) filtering glass (scenario A10_F; G channel, manual threshold with best fitness), and (c) natural sand (scenario B6_S; Cr channel, manual threshold with best fitness).

The migration and entrapment behavior is different for each type of porous medium. The migration velocity is the largest in glass beads. In contrast, at least for the first time steps, it is nearly equal for both filtering glass and natural sand. The degree of "heterogeneity" in source zone shape correlates with the irregularity of the grains, i.e., glass beads lead to the most regular and sand to the most irregular SZG. Furthermore, fingering effects, as well as the amount of entrapped DNAPL volumes, clearly correlate with grain irregularity. The influence of small porosity changes through irregular grain diameter and shape leads to nearly horizontally aligned entrapped DNAPL volumes. Overall, the observed DNAPL migration and entrapment behavior fulfills all expectations, which supports the applicability of both the experimental setup and the IPA framework configuration. 


\section{Conclusions}

\subsection{Summary}

In this study, a literature review was conducted to evaluate the current knowledge on image processing approaches for the evaluation of laboratory-scale hydraulic investigations. A large number of studies have used image processing for enhancing the area of interest, for excluding background information, and for calculating measures of interest, such as solute concentrations or phase saturations. However, up to now, no generalized IPA framework exists. Every study applies different IPA methodologies that may not be comparable or reproducible. In addition, uncertainties that are related to IPA have yet not been analyzed and compared to other uncertainties (e.g., given by the experimental setup).

Clearly defined DNAPL release scenarios involving three different porous media and nine different dyes in the visible light spectrum were used in laboratory-scale investigations under controlled environment in order to delineate and test a potentially generalizable IPA framework. The suitability of different dye configurations for DNAPL release studies was evaluated in batch experiments before running DNAPL release scenarios in a quasi-two-dimensional tank under controlled conditions. This allowed for us to identify 16 different suitable dye configurations for tank experiments from 60 different scenarios. Issues with appropriate dying of HFE-7100 by organic dyes were overcome while using dyes that colorize the aqueous phase. Furthermore, the combined use of aqueous and non-wetting phase dyes led to clearly improved visual separation of both fluid phases.

The sixteen different DNAPL release scenarios revealed that reflective optical imaging is an appropriate method for visualizing DNAPL migration and entrapment in different artificial and natural porous media of a single-size fraction. Filtering glass is a promising alternative to cost-intensive spherical glass beads due to its good semi-transparency and irregular grain shape, representing more natural non-consolidated porous media properties that are relevant for DNAPL migration and entrapment (except porosity values).

The IPA framework was applied to all sixteen DNAPL release scenarios to determine the sensitivity and relevance of each IPA step. Our analyses show that reliable results are only given through an appropriate combination of porous media type, dye configuration, and IPA steps. A temporal illumination fluctuation correction through white balance adjustment is recommended for all types of porous media. A straightforward conversion from sRGB to grayscale could not clearly separate the SZG from the background, so an appropriate single channel should be selected after comparing all channel possibilities. Background exclusion and spatially non-uniform illumination correction were achieved via difference image calculation. Overall, with an optimized IPA framework configuration, it was possible to calculate DNAPL saturation distributions for all three types of porous media. Good fitness values against the experimentally determined volume balance values were achieved. IPA-related uncertainties are within a range of approx. $1 \%$ (best dye configuration) to $41 \%$ (worst dye configuration), depending on the choice of dye configuration and single channel. With the IPA framework, the expected DNAPL migration and entrapment behavior was successfully visualized.

\subsection{Limitations and Outlook}

Further IPA steps may be required to exaggerate the area of interest and to exclude optical noise emerging from non-ideal experimental conditions for non-consolidated porous media with high non-uniformity due to inhomogeneous size and spectral appearance of grains (e.g., slight changes in camera positioning relative to tank setup). As the binary conversion algorithms adaptive Gaussian and mean (both with different amount of neighbor pixels) led to mostly unusable results due to optical noise, advanced filtering approaches, such as Gaussian filter, can bear potential improvements. However, their application might partly lead to information loss (e.g., for small areas of entrapped DNAPL volumes). 
In some cases, single channels may not contain enough spectral contrast to distinguish between separate phases (i.e., the amount and amplitude of peaks within the grayscale spectrum is low and covers many gray levels). Here, algorithms, such as contrast-limited adaptive histogram equalization (see ESM A1), may provide an appropriate means to increase image contrast. However, depending on setup properties (e.g., porous medium type, illumination, dye configuration), attention should be paid for the parameterization of such algorithms to avoid optical noise leading to implausible saturation profiles.

In this work, DNAPL saturation was calculated by overlaying a regular mesh in the binary image and by the subsequent calculation of WBPR values. Other opportunities, such as fitting an analytical function to parts of the grayscale spectrum with calibration against measured color intensities of known DNAPL saturation (e.g., shaking cube experiment), should be evaluated and compared with the method applied here. In addition, the verification measure $Q C$ used in this work does not consider volumetric uncertainties while assuming negligible wall and three-dimensional migration effects. Here, other sensors (e.g., geophysical methods) may serve as an additional data source to verify IPA steps identified as optimal for DNAPL release scenarios. Alternatively, as a more straightforward approach, images that were taken from the front and back tank walls could evaluate the influence of the previously mentioned effects.

The latter should be tested for different experimental setups (e.g., water-unsaturated soils, LNAPL compounds, saltwater intrusion), other non-consolidated porous media (e.g., silty sand, clay lenses, combinations of several sediment fractions), and fractured rock (e.g., sandstone, limestone) in order to point out the flexibility and transferability of the IPA framework presented here.

Supplementary Materials: The following are available online at http://www.mdpi.com/2073-4441/11/11/2274/s1. Electronic Supplementary Material S1: "Unprocessed raw TIFF format images used for IPA framework evaluation"; Electronic Supplementary Material S2: "Sensitivities of color model change and binary conversion algorithms"; Electronic Supplementary Material S3 "Relevance of spatially non-uniform illumination correction and background exclusion".

Author Contributions: Conceptualization, C.E.; Funding acquisition, C.E. and M.W.; Investigation, C.E. and L.S.; Methodology, C.E., L.S. and C.J.W.; Project administration, M.W.; Software, C.E. and L.S.; Supervision, C.J.W. and M.W.; Validation, C.E., L.S. and M.W.; Visualization, C.E. and L.S.; Writing-original draft, C.E.; Writing-review \& editing, C.E., L.S., C.J.W. and M.W.

Funding: This work was funded by the Deutsche Forschungsgemeinschaft (DFG, German Research Foundation) (grant numbers WA 3973/2-1, LI 727/29-1 as well as DI 833/22-1).

Acknowledgments: We thank Martin Binder for discussions related to the experimental works and internal review. Sharif Ibne Ibrahim is acknowledged for conducting the hydraulic characterization of the porous media used.

Conflicts of Interest: The authors declare no conflict of interest. The funders had no role in the design of the study, in the collection, analyses or interpretation of data; in the writing of the manuscript, or in the decision to publish the results.

\section{Appendix A}

Table A1. Summary of most relevant existing IPA approaches, their outcome and selected references.

\begin{tabular}{cccc}
\hline Aim & IPA Step & \multicolumn{2}{c}{ Exemplary References } \\
\cline { 3 - 4 } & NAPL-Related & Other \\
\hline $\begin{array}{c}\text { Correction of temporal } \\
\text { illumination fluctuations }\end{array}$ & $\begin{array}{c}\text { Image normalization using black } \\
\text { and white cards or grey cards } \\
\text { Correction using white card or gray } \\
\text { card or reference areas } \\
\text { Standardization of image }\end{array}$ & {$[56]$} & {$[66,76]$} \\
{$\left[\begin{array}{c}\text { Color model change to } \\
\text { uncover required } \\
\text { information }\end{array}\right.$} & Conversion to HSI or YCbCr & {$[60,77,78]$} & {$[69,79]$} \\
\hline
\end{tabular}


Table A1. Cont.

\begin{tabular}{|c|c|c|c|}
\hline \multirow{2}{*}{ Aim } & \multirow{2}{*}{ IPA Step } & \multicolumn{2}{|c|}{ Exemplary References } \\
\hline & & NAPL-Related & Other \\
\hline \multirow{3}{*}{$\begin{array}{c}\text { Acquisition of } \\
\text { monochromatic image and } \\
\text { uncover required information } \\
\text { (e.g., to identify peaks) }\end{array}$} & Recording gray-scale image & [56] & {$[71,76,81]$} \\
\hline & Using single band of RGB or HSI & {$[34,49,80]$} & {$[56,62,66,68,76,78,79]$} \\
\hline & Converting to gray scale & [48] & {$[82,83]$} \\
\hline $\begin{array}{l}\text { Correction of spatially } \\
\text { non-uniform illumination }\end{array}$ & $\begin{array}{l}\text { Correction using a reference image, } \\
\text { either flat-field image or without } \\
\text { tracer and then dividing, subtracting } \\
\text { or normalizing to the image } \\
\text { Converting by using adaptive } \\
\text { thresholding algorithm using } \\
\text { percent distance between peaks }\end{array}$ & {$[30]$} & {$[62,84,85]$} \\
\hline \multirow{4}{*}{ Contrast enhancement } & Gamma correction & - & [77] \\
\hline & Color balance adjustment & [70] & - \\
\hline & Adjustment of luminescence level & {$[70]$} & - \\
\hline & CLAHE with Rayleigh distribution & - & [71] \\
\hline \multicolumn{4}{|l|}{$\begin{array}{l}\text { Reduction to area of interest, } \\
\text { i.e., cut image to relevant } \\
\text { size and to exclude } \\
\text { background such as } \\
\text { tank set-up }\end{array}$} \\
\hline \multirow{5}{*}{ Reduction of optical noise } & Median filter & - & {$[66,79,82]$} \\
\hline & $\begin{array}{c}\text { Image smoothing using } 7 \times 7 \text { filter } \\
\text { window, filter is just applied if a } \\
\text { specific threshold is exceeded } \\
\text { Acquiring a reflection image, } \\
\text { which is a map of incident } \\
\text { disturbances based on the soil } \\
\text { particles for correcting surface } \\
\text { roughness and varying optical } \\
\text { properties of the soil }\end{array}$ & - & [85] \\
\hline & Morphological opening operation & - & {$[71,72]$} \\
\hline & Wavelet de-noising & - & {$[71]$} \\
\hline & $\begin{array}{l}\text { Image subtraction with reference } \\
\text { image (generally image } \\
\text { without Tracer) }\end{array}$ & - & {$[62,84]$} \\
\hline \multirow{3}{*}{ Background elimination } & $\begin{array}{l}\text { Image subtraction with reference } \\
\text { image (generally image } \\
\text { without Tracer) }\end{array}$ & [48] & {$[37,66]$} \\
\hline & Background leveling & - & [79] \\
\hline & $\begin{array}{l}\text { Thresholding based on fuzzy } \\
\text { partition and tsallis entropy }\end{array}$ & - & {$[71]$} \\
\hline $\begin{array}{l}\text { Adaption to representative } \\
\text { elementary volume }\end{array}$ & $\begin{array}{l}\text { Averaging RGB values for, } \\
\text { e.g., } 2 \times 2 \text { pixel }\end{array}$ & - & [37] \\
\hline Identifying object of interest & $\begin{array}{l}\text { Defining mean threshold for } \\
\text { background and object of interest }\end{array}$ & - & {$[72,85]$} \\
\hline De-blurring image & Unsharpness filtering & - & [71] \\
\hline \multirow[b]{3}{*}{ Acquisition of binary image } & Converting to black and white & [70] & - \\
\hline & $\begin{array}{l}\text { Converting to } \mathrm{b} / \mathrm{w} \text { using } \\
\text { specific threshold }\end{array}$ & {$[34]$} & {$[71]$} \\
\hline & $\begin{array}{l}\text { Converting by using adaptive } \\
\text { thresholding algorithm using } \\
\text { percent distance between peaks }\end{array}$ & {$[30]$} & - \\
\hline Delineate NAPL saturation & Mesh overlay & {$[34]$} & - \\
\hline
\end{tabular}


Table A2. Batch scenarios for evaluating different dye configurations. The type defines which phase was dyed (only aqueous phase, only non-wetting phase, or both).

\begin{tabular}{|c|c|c|c|c|c|c|c|c|c|c|}
\hline ID & Type & $\begin{array}{l}\text { Aqueous } \\
\text { Phase Dye }\end{array}$ & $\begin{array}{l}\text { DNAPL } \\
\text { Phase Dye }\end{array}$ & $\begin{array}{l}\text { Non-Horizontal } \\
\text { Phase Interface }\end{array}$ & $\begin{array}{l}\text { Gradient } \\
\text { Interface }\end{array}$ & $\begin{array}{c}\text { Poor Color } \\
\text { Contrast } \\
\text { between Phases }\end{array}$ & $\begin{array}{c}\text { Poor Color Contrast } \\
\text { between Fluid and } \\
\text { Sediment }\end{array}$ & $\begin{array}{l}\text { Sorption to } \\
\text { Sediment }\end{array}$ & $\begin{array}{c}\text { Photo- } \\
\text { Degradation }\end{array}$ & $\begin{array}{c}\text { Not } \\
\text { Suitable }\end{array}$ \\
\hline $\begin{array}{l}\text { A1_G } \\
\text { A1_F } \\
\text { A1_S }\end{array}$ & Dual & $\begin{array}{l}\text { Indigo } \\
\text { carmine }\end{array}$ & Oil-Red-O & Yes & Yes & No & $\begin{array}{l}\text { Not tested } \\
\text { Not tested } \\
\text { Not tested }\end{array}$ & $\begin{array}{l}\text { Not tested } \\
\text { Not tested } \\
\text { Not tested }\end{array}$ & No & $\begin{array}{l}\text { Yes } \\
\text { Yes } \\
\text { Yes }\end{array}$ \\
\hline $\begin{array}{l}\text { A2_G } \\
\text { A2_F } \\
\text { A2_S }\end{array}$ & Dual & $\begin{array}{l}\text { Indigo } \\
\text { carmine }\end{array}$ & Sudan IV & No & No & No & $\begin{array}{c}\text { No } \\
\text { No } \\
\text { Not tested }\end{array}$ & $\begin{array}{l}\text { Not tested } \\
\text { Not tested } \\
\text { Not tested }\end{array}$ & No & $\begin{array}{l}\text { No } \\
\text { No } \\
\text { Yes }\end{array}$ \\
\hline $\begin{array}{l}\text { A3_G } \\
\text { A3_F } \\
\text { A3_S }\end{array}$ & Dual & $\begin{array}{l}\text { Brilliant } \\
\text { Blue FCF }\end{array}$ & Oil-Red-O & Yes & Yes & No & $\begin{array}{l}\text { Not tested } \\
\text { Not tested } \\
\text { Not tested }\end{array}$ & $\begin{array}{l}\text { Not tested } \\
\text { Not tested } \\
\text { Not tested }\end{array}$ & No & $\begin{array}{l}\text { Yes } \\
\text { Yes } \\
\text { Yes }\end{array}$ \\
\hline $\begin{array}{l}\text { A4_G } \\
\text { A4_F } \\
\text { A4_S }\end{array}$ & Dual & $\begin{array}{l}\text { Brilliant } \\
\text { Blue FCF }\end{array}$ & Sudan IV & No & No & No & $\begin{array}{l}\text { No } \\
\text { No } \\
\text { No }\end{array}$ & $\begin{array}{l}\text { Not tested } \\
\text { Not tested } \\
\text { Not tested }\end{array}$ & No & $\begin{array}{l}\text { No } \\
\text { No } \\
\text { No }\end{array}$ \\
\hline $\begin{array}{l}\text { A5_G } \\
\text { A5_F } \\
\text { A5_S }\end{array}$ & Dual & Rhodamine-B & $\begin{array}{l}\text { Sudan } \\
\text { Blue }\end{array}$ & No & No & Yes & $\begin{array}{l}\text { Not tested } \\
\text { Not tested } \\
\text { Not tested }\end{array}$ & $\begin{array}{l}\text { Not tested } \\
\text { Not tested } \\
\text { Not tested }\end{array}$ & No & $\begin{array}{l}\text { Yes } \\
\text { Yes } \\
\text { Yes }\end{array}$ \\
\hline $\begin{array}{l}\text { A7_G } \\
\text { A7_F } \\
\text { A7_S }\end{array}$ & Dual & Blue pen ink & Oil-Red-O & No & Yes & No & $\begin{array}{l}\text { Not tested } \\
\text { Not tested } \\
\text { Not tested }\end{array}$ & $\begin{array}{l}\text { Not tested } \\
\text { Not tested } \\
\text { Not tested }\end{array}$ & No & $\begin{array}{l}\text { Yes } \\
\text { Yes } \\
\text { Yes }\end{array}$ \\
\hline $\begin{array}{l}\text { A8_G } \\
\text { A8_F } \\
\text { A8_S }\end{array}$ & Dual & Blue pen ink & Sudan IV & No & Yes & No & $\begin{array}{l}\text { Not tested } \\
\text { Not tested } \\
\text { Not tested }\end{array}$ & $\begin{array}{l}\text { Not tested } \\
\text { Not tested } \\
\text { Not tested }\end{array}$ & No & $\begin{array}{l}\text { Yes } \\
\text { Yes } \\
\text { Yes }\end{array}$ \\
\hline $\begin{array}{l}\text { A9_G } \\
\text { A9_F } \\
\text { A9_S }\end{array}$ & Dual & $\begin{array}{l}\text { Green pen } \\
\text { ink }\end{array}$ & Oil-Red-O & Yes & Yes & No & $\begin{array}{l}\text { Not tested } \\
\text { Not tested } \\
\text { Not tested }\end{array}$ & $\begin{array}{l}\text { Not tested } \\
\text { Not tested } \\
\text { Not tested }\end{array}$ & No & $\begin{array}{l}\text { Yes } \\
\text { Yes } \\
\text { Yes }\end{array}$ \\
\hline $\begin{array}{l}\text { A10_G } \\
\text { A10_F } \\
\text { A10_S }\end{array}$ & Dual & $\begin{array}{l}\text { Green pen } \\
\text { ink }\end{array}$ & Sudan IV & No & No & No & $\begin{array}{l}\text { No } \\
\text { No } \\
\text { No }\end{array}$ & $\begin{array}{l}\text { Not tested } \\
\text { Not tested } \\
\text { Not tested }\end{array}$ & No & $\begin{array}{l}\text { No } \\
\text { No } \\
\text { No }\end{array}$ \\
\hline
\end{tabular}


Table A2. Cont.

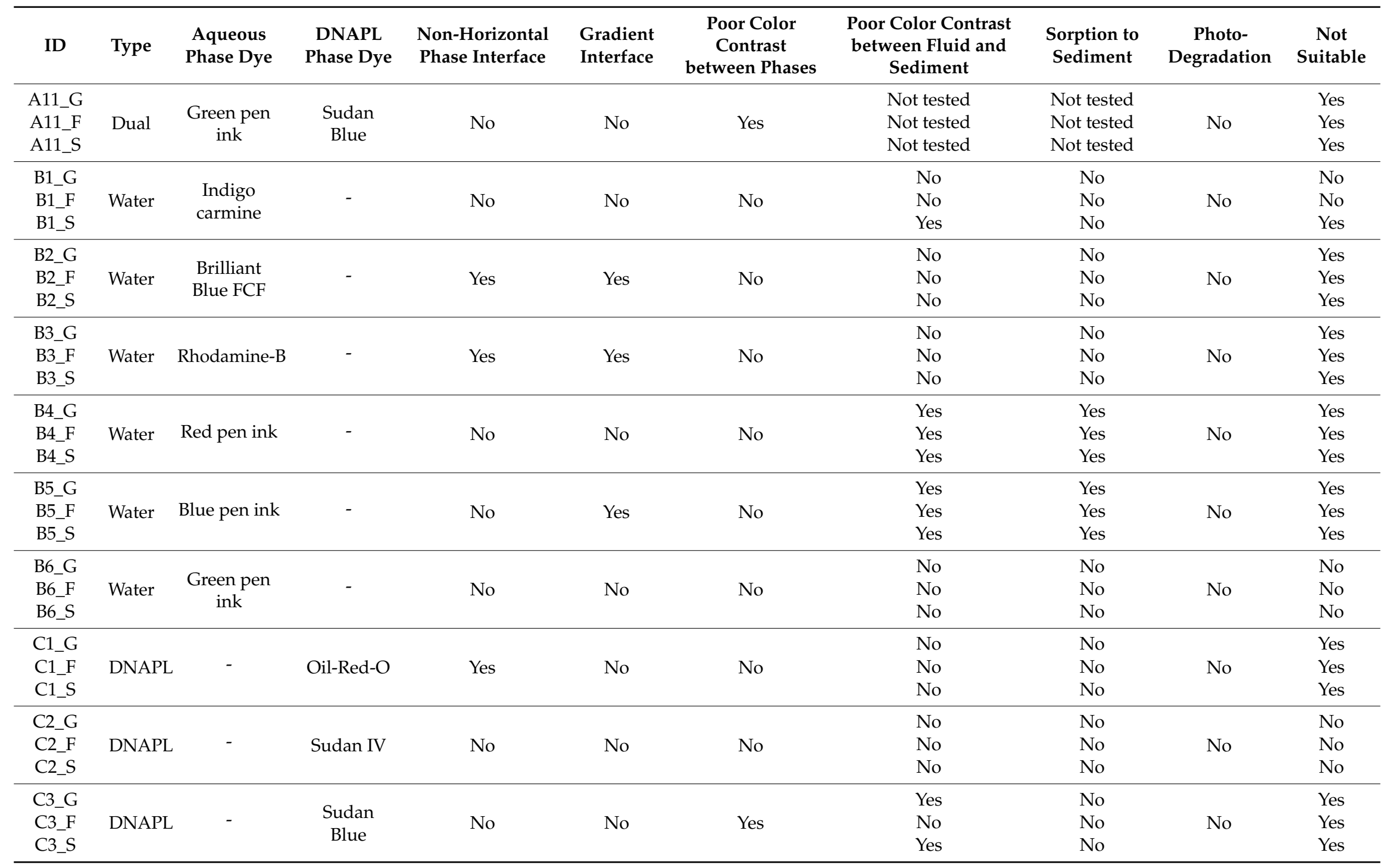




\section{References}

1. Mackay, D.M.; Cherry, J.A. Groundwater contamination: Pump-and-treat remediation. Environ. Sci. Technol. 1989, 23, 630-636. [CrossRef]

2. European Commission (EC). Regulation No. 850/2004 of the European Parliament and of the Council of 29 April 2004 on Persistent Organic Pollutants and Amending Directive 79/117/EEC. 2004, p. 31. Available online: https://eur-lex.europa.eu/legal-content/EN/TXT/PDF/?uri=CELEX:02004R0850-20120710\&from=EN (accessed on 23 August 2019).

3. Engelmann, C.; Händel, F.; Binder, M.; Yadav, P.K.; Dietrich, P.; Liedl, R.; Walther, M. The fate of DNAPL contaminants in non-consolidated subsurface systems-Discussion on the relevance of effective source zone geometries for plume propagation. J. Hazard. Mat. 2019, 375, 233-240. [CrossRef] [PubMed]

4. Kueper, B.H.; Stroo, H.F.; Vogel, C.M.; Ward, C.H. (Eds.) Chlorinated Solvent Source Zone Remediation; Springer: New York, NY, USA; Heidelberg, Germany; Dordrecht, The Netherlands; London, UK, 2014; p. 713.

5. Agaoglu, B.; Copty, N.K.; Scheytt, T.; Hinkelmann, R. Interphase mass transfer between fluids in subsurface formations: A review. Adv. Water Resour. 2015, 79, 162-194. [CrossRef]

6. Powers, S.E.; Nambi, I.M.; Curry, G.W., Jr. Non-aqueous phase liquid dissolution in heterogeneous systems: Mechanisms and a local equilibrium modeling approach. Water Resour. Res. 1998, 34, 3293-3302. [CrossRef]

7. Brusseau, M.L.; Hatton, J.; DiGuiseppi, W. Assessing the impact of source-zone remediation efforts at the contaminant-plume scale through analysis of contaminant mass discharge. J. Contam. Hydrol. 2011, 126, 130-139. [CrossRef] [PubMed]

8. Wiedemeier, T.; Rifai, H.; Newell, C.; Wilson, J. Natural Attenuation of Fuels and Chlorinated Solvents in the Subsurface; John Wiley \& Sons, Inc.: Hoboken, NY, USA, 1999; p. 619.

9. Falta, R.W.; Basu, N.; Rao, P.S.C. Assessing impacts of partial mass depletion in DNAPL source zones: II, coupling source strength functions to plume evolution. J. Contam. Hydrol. 2005, 79, 45-66. [CrossRef]

10. Fure, A.D.; Jawitz, J.W.; Annable, M.D. DNAPL source depletion: Linking architecture and flux response. J. Contam. Hydrol. 2006, 85, 118-140. [CrossRef]

11. Liedl, R.; Valocchi, A.J.; Dietrich, P.; Grathwohl, P. Finiteness of steady state plumes. Water Resour. Res. 2005, 41,1-8. [CrossRef]

12. Brusseau, M.L.; Nelson, N.T.; Zhang, Z.; Blue, J.E.; Rohrer, J.; Allen, T. Source-zone characterization of a chlorinated-solvent contaminated superfund site in Tuscon, AZ. J. Contam. Hydrol. 2007, 90, 21-40. [CrossRef]

13. Sookhak Lari, K.; Davis, G.B.; Rayner, J.L.; Bastow, T.P.; Puzon, G.J. Natural Source zone depletion of LNAPL: A critical review supporting modelling approaches. Water Res. 2019, 157, 630-646. [CrossRef]

14. Werth, C.J.; Zhang, C.; Brusseau, M.L.; Oostrom, M.; Baumann, T. A review of non-invasive imaging methods and applications in contaminant hydrogeology research. J. Contam. Hydrol. 2010, 113, 1-24. [CrossRef] [PubMed]

15. Cnudde, V.; Boone, M.N. high-resolution X-ray computed tomography in geosciences: A review of the current technology and applications. Earth-Sci. Rev. 2013, 123, 1-17. [CrossRef]

16. Power, C.; Gerhard, J.I.; Tsourlos, P.; Soupios, P.; Simyrdanis, K.; Karaoulis, M. Improved time-lapse electrical resistivity tomography monitoring of dense non-aqueous phase liquids with surface-to-horizontal borehole arrays. J. Appl. Geosci. 2015, 112, 1-13. [CrossRef]

17. Alesse, B.; Orlando, L.; Palladini, L. Non-invasive lab test in the monitoring of vadose zone contaminated by light non-aqueous phase liquid. Geophys. Prosp. 2019. [CrossRef]

18. Zhang, C.; Yoon, H.; Werth, C.J.; Valocchi, A.J.; Basu, N.B.; Jawitz, J.W. Evaluation of simplified mass transfer models to simulate the impacts of source zone architecture on nonaqueous phase liquid dissolution in heterogeneous porous media. J. Contam. Hydrol. 2008, 102, 49-60. [CrossRef] [PubMed]

19. Mazáč, O.; Kelly, W.E.; Landa, I. A hydrogeophysical model for relations between electrical and hydraulic properties of aquifers. J. Hydrol. 1985, 79, 1-19. [CrossRef]

20. Dietrich, P.; Fechner, T.; Whittaker, J. Anmerkungen zur Interpretation tomographischer Messungen. In Proceedings of the DGG-Mitteilungen Sonderband II/1999-5. DGG-Seminar "Umweltgeophysik", Neustadt, Germany, April 1998; pp. 13-21.

21. Huang, W.E.; Smith, C.C.; Lerner, D.N.; Thornton, S.F.; Oram, A. Physical modelling of solute transport in porous media: Evaluation of an imaging technique using UV excited fluorescent dye. Water Res. 2002, 36, 1843-1853. [CrossRef] 
22. Peng, Z.; Duwig, C.; Delmas, P.; Gaudet, J.P.; Gastelum Strozzi, A.; Charrier, P.; Denis, H. Visualization and Characterization of Heterogeneous Water Flow in Double-Porosity Media by Means of X-ray Computed Tomography. Transp. Porous Med. 2015, 110, 543-564. [CrossRef]

23. Maas, H.-G.; Hampel, U. Photogrammetric Techniques in Civil Engineering Material Testing and Structure Monitoring. Photogram. Eng. Rem. Sens. 2006, 1, 39-45. [CrossRef]

24. Konz, M.; Ackerer, P.; Younes, A.; Huggenberger, P.; Zechner, E. Two-dimensional stable-layered laboratory-scale experiments for testing density-coupled flow models. Water Resour. Res. 2009, 45, W02404. [CrossRef]

25. Robinson, G.; Ahmed, A.A.; Hamill, G.A. Experimental saltwater intrusion in coastal aquifers using automated image analysis: Applications to homogeneous aquifers. J. Hydrol. 2016, 538, 304-313. [CrossRef]

26. Stoeckl, L.; Walther, M.; Graf, T. A new numerical benchmark of a freshwater lens. Water Resour. Res. 2016, 52, 2474-2489. [CrossRef]

27. Stoeckl, L.; Walther, M.; Morgan, L.K. Physical and Numerical Modelling of Post-Pumping Seawater Intrusion. Geofluids 2019, 7191370. [CrossRef]

28. Cohen, R.M.; Bryda, A.P.; Shaw, S.T.; Spalding, C.P. Evaluation of Visual Methods to Detect NAPL in Soil and Water. Groundwater Monit. Remed. 1992, 12, 132-141. [CrossRef]

29. Glass, R.J.; Conrad, S.H.; Peplinski, W. Gravity-destabilized nonwetting phase invasion in macroheterogeneous porous media: Experimental observations of invasion dynamics and scale analysis. Water Resour. Res. 2000, 36, 3121-3137. [CrossRef]

30. Zhong, L.; Mayer, A.; Glass, R.J. Visualization of surfactant-enhanced nonaqueous phase liquid mobilization and solubilization in a two-dimensional micromodel. Water Resour. Res. 2001, 37, 523-537. [CrossRef]

31. Oostrom, M.; Dane, J.H.; Wietsma, T.W. A Review of Multidimensional, Multifluid, Intermediate-Scale Experiments: Flow Behavior, Saturation Imaging, and Tracer Detection and Quantification. Vadose Zone J. 2007, 6. [CrossRef]

32. Page, J.W.E.; Soga, K.; Illangasekare, T. The significance of heterogeneity on mass flux from DNAPL source zones: An experimental investigation. J. Contam. Hydrol. 2007, 94, 215-234. [CrossRef]

33. Bob, M.M.; Brooks, M.C.; Mravik, S.C.; Wood, L. A modified light transmission visualization method for DNAPL saturation measurements in 2-D models. Adv. Water Resour. 2008, 31, 727-742. [CrossRef]

34. Luciano, A.; Viotti, P.; Papini, M.P. Laboratory investigation of DNAPL migration in porous media. J. Hazard. Mat. 2010, 176, 1006-1017. [CrossRef]

35. Luciano, A.; Viotti, P.; Papini, M.P. On Morphometric Properties of DNAPL Sources: Relating Architecture to Mass Reduction. Water Air Soil Pollut. 2012, 223, 2849-2864. [CrossRef]

36. Luciano, A.; Manchini, G.; Torretta, V.; Viotti, P. An empirical model for the evaluation of the dissolution rate from a DNAPL-contaminated area. Environ. Sci. Pollut. Res. 2018, 25, 33992-34004. [CrossRef] [PubMed]

37. Citarella, D.; Cupola, F.; Tanda, M.G.; Zanini, A. Evaluation of dispersivity coefficients by means of a laboratory image analysis. J. Contam. Hydrol. 2015, 172, 10-23. [CrossRef] [PubMed]

38. Kashuk, S.; Mercurio, S.R.; Iskander, M. Visualization of dyed NAPL concentration in transparent porous media using color space components. J. Contam. Hydrol. 2014, 162-163, 1-16. [CrossRef] [PubMed]

39. Kashuk, S.; Mercurio, S.R.; Iskander, M. Methodology for Optical Imaging of NAPL 3D Distribution in Transparent Porous Media. Geotech. Test. J. 2015, 38, 603-619. [CrossRef]

40. Pan, Y.; Yang, J.; Jia, Y.; Xu, Z. Experimental study on non-aqueous phase liquid multiphase flow characteristics and controlling factors in heterogeneous porous media. Environ. Earth Sci. 2016, 75. [CrossRef]

41. Wu, M.; Cheng, Z.; Wu, J.; Wu, J. Estimation of representative elementary volume for DNAPL saturation and DNAPL-water interfacial areas in 2D heterogeneous porous media. J. Hydrol. 2017, 549, 12-26. [CrossRef]

42. Rahman, N.A.; Foong, L.K.; Lewis, R.W.; Nazir, R. Laboratory Investigation of LNAPL Migration in Double-Porosity Soil Under Fractured Condition Using Digital Image Analysis. Transp. Porous Med. 2018, 125, 521-542. [CrossRef]

43. Gonzales, R.C.; Woods, R.E. Digital Image Processing, 2nd ed.; Prentice Hall: Upper Saddle River, NJ, USA, 2002; p. 793.

44. Singh, P.; Garg, A.K. Non Uniform Background Removal using Morphology based Structuring Element for Particle Analysis. Int. J. Comp. Appl. 2011, 33, 11-16.

45. Robinson, G.; Hamill, G.A.; Ahmed, A.A. Automated image analysis for experimental investigations of salt water intrusion in coastal aquifers. J. Hydrol. 2015, 530, 350-360. [CrossRef] 
46. Detwiler, R.L.; Pringle, S.E.; Glass, R.J. Measurement of fracture aperture fields using transmitted light: An evaluation of measurement errors and their influence on simulations of flow and transport through a single fracture. Water Resour. Res. 1999, 35, 2605-2617. [CrossRef]

47. Abdoulhalik, A.; Ahmed, A.A. Transience of seawater intrusion and retreat in response to incremental water-level variations. Hydrol. Proc. 2018, 32, 2721-2733. [CrossRef]

48. Alazaiza, M.Y.D.; Ngien, S.K.; Copty, N.; Bob, M.M.; Kamaruddin, S.A. Assessing the influence of infiltration on the migration of light non-aqueous phase liquid in double-porosity soil media using a light transmission visualization method. Hydrogeol. J. 2019, 27, 581-593. [CrossRef]

49. Gerhard, J.I.; Kueper, B.H. Capillary pressure characteristics necessary for simulating DNAPL infiltration, redistribution, and immobilization in saturated porous media. Water Resour. Res. 2003, 39, 1212. [CrossRef]

50. Rezanezhad, F.; Vogel, H.-J.; Roth, K. Experimental study of fingered flow through initially dry sand. Hydrol. Earth Syst. Sci. Discuss. EGU 2006, 3, 2595-2620. [CrossRef]

51. Konz, M.; Ackerer, P.; Huggenberger, P.; Veit, C. Comparison of light transmission and reflection techniques to determine concentrations in flow tank experiments. Exp. Fluids 2009, 47, 85. [CrossRef]

52. Sabnis, R.W. Handbook of Biological Dyes and Stains: Synthesis and Industrial Applications; John Wiley \& Sons: Hoboken, NJ, USA, 2010; p. 544.

53. Cápiro, N.L.; Stafford, B.P.; Rixey, W.G.; Bedient, P.B.; Alvarez, P.J.J. Fuel-grade ethanol transport and impacts to groundwater in a pilot-scale aquifer tank. Water Res. 2007, 41, 656-664. [CrossRef]

54. Nsir, K.; Schäfer, G.; di Chiara Roupert, R.; Razakarisoa, O.; Toussaint, R. Laboratory experiments on DNAPL fingering in water-saturated porous media. Int. J. Multiph. Flow 2012, 40, 83-92. [CrossRef]

55. Jawitz, J.W.; Annable, M.D.; Rao, P.S.C. Miscible fluid displacement stability in unconfined porous media: Two-dimensional flow experiments and simulations. J. Contam. Hydrol. 1998, 31, 211-230. [CrossRef]

56. Kechavarzi, C.; Soga, K.; Wiart, P. Multispectral image analysis method to determine dynamic fluid saturation distribution in two-dimensional three-fluid phase flow laboratory experiments. J. Contam. Hydrol. 2000, 46, 265-293. [CrossRef]

57. Brusseau, M.; Nelson, N.T.; Oostrom, M.; Zhang, Z.; Johnson, G.R.; Wietsma, T.W. Influence of Heterogeneity and Sampling Method on Aqueous Concentrations Associated with NAPL Dissolution. Environ. Sci. Technol. 2000, 34, 3657-3664. [CrossRef]

58. Ghanem, A.; Soerens, T.S.; Adel, M.M.; Thoma, G.J. Investigation of Fluorescent Dyes as Partitioning Tracers for Subsurface Nonaqueous Phase Liquid (NAPL) Characterization. J. Environ. Eng. 2003, 129, 740. [CrossRef]

59. Käss, W. Lehrbuch der Hydrogeologie, Band 9: Geologische Markierungstechnik (Textbook of geohydrological marking and tracing techniques, vol. 9, 2nd edn.); Borntraeger: Berlin, Germany, 2004; p. 557.

60. Barns, G.L.; Wilson, R.D.; Thornton, S.F. Fluorescent dye imaging of the volume sampled by single well forced-gradient tracer tests evaluated in a laboratory-scale aquifer physical model. J. Contam. Hydrol. 2012, 128, 58-70. [CrossRef] [PubMed]

61. Barns, G.L.; Thornton, S.F.; Wilson, R.D. Identification of small-scale low and high permeability layers using single well forced-gradient tracer tests: Fluorescent dye imaging and modelling at the laboratory scale. J. Contam. Hydrol. 2015, 172, 84-99. [CrossRef] [PubMed]

62. Ilankoon, I.M.S.K.; Neethling, S.J. Inter-particle liquid spread pertaining to heap leaching using UV fluorescence based image analysis. Hydrometallurgy 2019, 183, 175-185. [CrossRef]

63. Davis, S.N.; Thompson, G.M.; Bentley, H.W.; Stiles, G. Ground-Water Tracers-A Short Review. Groundwater 1980, 18, 14-23. [CrossRef]

64. Tuck, D.M.; Iversen, G.M.; Pirkle, W.A. Organic dye effects on dense nonaqueous phase liquids (DNAPL) entry pressure in water saturated porous media. Water Resour. Res. 2003, 39, 1207. [CrossRef]

65. Stoeckl, L.; Houben, G. Flow dynamics and age stratification of freshwater lenses: Experiments and modeling. J. Hydrol. 2012, 458-459, 9-15. [CrossRef]

66. Belfort, B.; Weill, S.; Lehmann, F. Image analysis method for the measurement of water saturation in a two-dimensional experimental flow tank. J. Hydrol. 2017, 550, 343-354. [CrossRef]

67. PSF (2018) Python Software Foundation. Python Language Reference, version 3.6. Available online: http://www.python.org (accessed on 29 October 2019).

68. Simantiraki, F.; Aivalioti, M.; Gidarakos, E. Implementation of an image analysis technique to determine LNAPL infiltration and distribution in unsaturated porous media. Desalination 2009, 248, 705-715. [CrossRef] 
69. Wang, Y.; Huang, Q.; Hu, J. Adaptive enhancement for nonuniform illumination images via nonlinear mapping. J. Electron. Imag. 2017, 26, 053012. [CrossRef]

70. Halihan, T.; Sefa, V.; Sale, T.; Lyverse, M. Mechanism for detecting NAPL using electrical resistivity imaging. J. Contam. Hydrol. 2017, 205, 57-69. [CrossRef] [PubMed]

71. Riaño, A.B.; Rodriguez, I.H.; Bannwart, A.C.; Rodriguez, O.M.H. Film thickness measurement in oil-water pipe flow using image processing technique. Exp. Therm. Fluid Sci. 2015, 68, 330-338. [CrossRef]

72. Zhang, Z.; Zhou, Y.; Liu, H.; Gao, H. In-situ water level measurement using NIR-imaging video camera. Flow Meas. Inst. 2019, 67, 95-106. [CrossRef]

73. Otsu, N. A threshold selection method from fray-level histograms. IEEE Trans. Syst. Man. Cybern. 1979, 9, 62-66. [CrossRef]

74. Van Valkenburg, M.E.; Annable, M. Mobilization and entry of DNAPL pools into finer sand media by cosolvents: Two-dimensional chamber studies. J. Contam. Hydrol. 2002, 59, 211-230. [CrossRef]

75. Kamon, M.; Endo, K.; Kawabata, J.; Inui, T.; Katsumi, T. Two-dimensional DNAPL migration affected by groundwater flow in unconfined aquifer. J. Hazard. Mat. 2004, 110, 1-12. [CrossRef]

76. Bridge, J.; Banwart, S.; Heathwaite, A. Noninvasive Quantitative Measurement of Colloid Transport in Mesoscale Porous Media Using Time Lapse Fluorescence Imaging. Environ. Sci. Technol. 2006, 40, 5930-5936. [CrossRef]

77. Rahman, M; Jose, S.; Nowak, W.; Cirpka, O. Experiments on vertical transverse mixing in a large-scale heterogeneous model aquifer. J. Contam. Hydrol. 2005, 80, 130-148. [CrossRef]

78. Konz, M.; Ackerer, P.; Meier, E.; Huggenberger, P.; Zechner, E.; Gechter, D. On the measurement of solute concentrations in 2-D flow tank experiments. Hydrol. Earth Sys. Sci. 2008, 12, 727-738. [CrossRef]

79. McNeil, J.D.; Oldenborger, G.A.; Schincariol, R.A. Quantitative imaging of contaminant distributions in heterogeneous porous media laboratory experiments. J. Contam. Hydrol. 2006, 84, 36-54. [CrossRef] [PubMed]

80. Darnault, C.J.G.; Throop, J.A.; DiCarlo, D.A.; Rimmer, A.; Steenhuis, T.S.; Parlange, J.-Y. Visualization by light transmission of oil and water contents in transient two-phase flow fields. J. Contam. Hydrol. 1998, 31, 337-348. [CrossRef]

81. Rossi, M.; Lehmann, P.; Ursino, N.; Ippisch, O.; Flühler, H. Solute mixing during imbibition and drainage in a macroscopically heterogeneous medium. Water Resour. Res. 2007, 43, 1-13. [CrossRef]

82. Zhang, Q.; Volker, R.E.; Lockington, D.A. Experimental investigation of contaminant transport in coastal groundwater. Adv. Environ. Res. 2002, 6, 229-237. [CrossRef]

83. Madhania, S.; Muharam, Y.; Winardi, S.; Purwanto, W.W. Mechanism of molasses-water mixing behavior in bioethanol fermenter. Experiments and CFD modeling. Energy Rep. 2019, 5, 454-461. [CrossRef]

84. Bridge, J.W.; Bannwart, S.A.; Heathwaite, A.L. High-Resolution Measurement of Pore Saturation and Colloid Removal Efficiency in Quartz Sand Using Fluorescence Imaging. Environ. Sci. Technol. 2007, 41, 8288-8294. [CrossRef]

85. Aeby, P.; Schultze, U.; Braichotte, D.; Bundt, M.; Moser-Boroumand, F.; Wydler, H.; Flühler, H. Fluorescence Imaging of Tracer Distributions in Soil Profiles. Environ. Sci. Technol. 2001, 35, 753-760. [CrossRef]

(C) 2019 by the authors. Licensee MDPI, Basel, Switzerland. This article is an open access article distributed under the terms and conditions of the Creative Commons Attribution (CC BY) license (http://creativecommons.org/licenses/by/4.0/). 